\title{
IF AT FIRST YOU DON'T SUCCEED...: \\ PROFITS, PRICES AND MARKET STRUCTURE IN A MODEL OF QUALITY WITH UNKNOWABLE CONSUMER HETEROGENEITY
}

\author{
Kala Krishna \\ Tor Winston \\ Working Paper 7494 \\ http://www.nber.org/papers/w7494 \\ NATIONAL BUREAU OF ECONOMIC RESEARCH \\ 1050 Massachusetts Avenue \\ Cambridge, MA 02138 \\ January 2000
}

An earlier version of this paper came out as NBER Working paper No. 6580. Kala Krishna gratefully acknowledges the financial support from the National Science Foundation, grants SBR-9320825 and SBR9725019 to the NBER and to The Pennsylvania State University respectively. The authors are grateful to Laura Bivins, Eric Bond, Kalyan Chatterjee, Tom Gresik, Eric Maskin, Motty Perry, Carolyn Pitchik, Marie Thursby, Torben Tranaes, Cemile Yavas and participants at workshops at Columbia University, the University of Copenhagen, and Penn State for useful comments. The views expressed herein are those of the author and not necessarily those of the National Bureau of Economic Research.

(C) 2000 by Kala Krishna and Tor Winston. All rights reserved. Short sections of text, not to exceed two paragraphs, may be quoted without explicit permission provided that full credit, including $\mathbb{O}$ notice, is given to the source. 
If at First You Don't Succeed...: Profits, Prices and Market Structure

in a Model of Quality with Unknowable Consumer Heterogeneity

Kala Krishna and Tor Winston

NBER Working Paper No. 7494

January 2000

JEL No. D4, D6, L1, L2

\section{ABSTRACT}

Why are higher quality niches seen as intrinsically more profitable in business circles? Why do high quality products sometimes have a low real price, while it is unusual to see low quality products with high real prices? Can markets have quality differentiation as well as quality bunching? In this paper we develop a new model of quality which explains such phenomena.

Our model builds on the idea that even if a customer chooses to purchase a product, it may fail to "deliver". If a product fails to deliver, the customer may wish to choose some other product. A higher quality product has a higher probability of delivering. We model this as a three stage game where firms first choose whether to enter or not, then in the second stage choose their quality and in the last stage, their price.

Our model has a number of interesting predictions. First, it suggests that in equilibrium, a wider range of price per unit of quality is to be found for high quality goods than for low quality ones.

Second, it provides a theoretical reason for why high quality niches may be more profitable, supporting the common business school idea that "the money is at the high end."

Third, it suggests that the nature of the fixed costs of establishing quality plays a critical role in determining when free entry could be consistent with the existence of profits and result in "natural oligopolies" and when it would tend to eliminate all profits.

Kala Krishna

Department of Economics

401 Kern Graduate Building

The Pennsylvania State University

University Park, PA 16802

and NBER

kmk4@psuvm.psu.edu
Tor Winston

Department of Economics

603 Kern Graduate Building

The Pennsylvania State University

University Park, PA 16802

torw@psu.edu 


\section{Introduction}

A casual observation of almost any market will reveal that firms compete on the basis of quality as much as on price, and that often high prices are justified by claims of high quality. Early contributions to the large economic literature of quality models followed a "services" approach, see [20]. According to this approach, a higher quality good merely embodied more services. Thus, a light bulb which lasted 200 hours was seen as being twice the quality of one which lasted only 100 hours. ${ }^{1}$ Later work interprets quality more generally as anything that would induce consumers to pay more. A variety of applications have been developed to explore issues such as the effect of regulation on quality, see [18] and [14], price discrimination by a monopolist in the presence of information problems, see [10], and the possibility of technological conditions resulting in natural oligopolies using models of vertical product differentiation as in [13].

In all these models, consumers choose to buy one product or another. In contrast to this, we look at a new model of quality which differs from the existing models in a number of ways. We assume that a consumer purchases a product knowing that it may fail to "deliver". If the product delivers, the consumer leaves the market with whatever payoff the product yields. If it does not deliver, the customer gets nothing ${ }^{2}$ and may wish to reenter the market to choose another product. This possibility of resampling is the primary difference between our model and others. Many situations have this flavor. For example, one auto repair shop may not fix a particular defect effectively so that another may have to be visited. One medical procedure may be unable to cure a patient while another approach may succeed. ${ }^{3}$

Shoes are an example which seems appealing to many people. A pair of shoes is rarely comfortable until it has been properly broken in. On examination one gets an idea of the probability that a particular pair of shoes will deliver the needed comfort level. Some shoes seem very likely to be comfortable, while others seem to have a lower probability of delivering comfort. This probability of "delivery" is what we call quality in our model and we assume that it is common and known to all consumers. It is possible that

\footnotetext{
${ }^{1}$ In these models firms minimize the cost per service and then choose the level of services which maximize profits.

${ }^{2}$ In ongoing work we are exploring the effect of variations on this assumption.

${ }^{3}$ Due to the possibility of returning to the market, the value of choosing a product differs from the payoff times the probability.
} 
high quality shoes, with a high probability of delivering, may not be truly comfortable. If shoes fail to deliver they are tossed to the back of the closet and the consumer may reenter the market to purchase a different brand. It is also possible that one might buy a low quality pair, with a low probability of delivering, if the price were right! Even though one brand of shoes may fail to deliver for one person, it may be a perfect fit for someone else. In effect, we assume that there is some underlying heterogeneity that cannot be known by either the consumer or the producer.

It is important to explain how our model differs from related models in the literature. First, failure in our model results from consumer-product incompatibility and not from product defects. In a model with defects, one may revisit a firm hoping not to receive a defective unit on the second try. This does not happen in our model because once a product has failed a consumer he will not purchase it again as he has already determined that it does not work for him. However, a product which does not work for one consumer may work for another due to the underlying unknowable heterogeneity we assume. Second, there is no asymmetric information or moral hazard since the underlying heterogeneity of consumers is unknowable by both consumers and producers and there is no way that the consumer can affect the probability of failure. Third, as our model is a static one there are no issues of learning or of strategic experimentation. In addition, there are no signalling issues as the probability of success is known. Goods in our model are not typical experience goods. Experience goods, whose characteristics are known only after they are tried, are often used to explain why consumers remain loyal to a known brand and are reluctant to switch to an unknown product which may not perform as well. Most such models contain some implicit or explicit dynamics which motivate the interpretation of consumer loyalty.

We develop our ideas in a simple setting. ${ }^{4}$ We assume that each firm makes only one product. We also assume that all firms and all consumers are ex ante identical which eliminates the usual reasons for product differentiation. In addition we assume that consumers can only use one unit of a good, but they may reenter the market if previous purchases have not delivered. This results in a perfectly inelastic demand curve for the consumer and eliminates traditional monopoly distortions from the model.

We model a three stage game where firms first choose whether to enter or

\footnotetext{
${ }^{4}$ This paper builds on Krishna and Winston (1998) which only deals with the two firm case.
} 
not, then in the second stage they choose quality, and in the last stage they choose price, given their previous quality choice. Our model has a number of interesting predictions.

First, it suggests that in equilibrium, a wider range of price per unit of quality is found for high quality goods than for low quality goods. It predicts that while one might find high quality products on sale at a low price per unit of quality, the opposite will not occur. It is unlikely for low quality products to be sold at a high price per unit of quality.

Second, our model provides a theoretical reason for why high quality niches may be more profitable, supporting the common business school idea that "the money is at the high end". 5 The standard response of economists to such claims is that not all relevant costs are accounted for. Investments in advertising, research and development or cultivation of a loyal customer base via early discounting, not high quality per se, are suggested as reasons for high current profits. In fact, in standard models of vertical product differentiation such as [13], higher quality firms may make lower profits once all costs are accounted for. ${ }^{6}$ In contrast, higher quality firms in our model make higher equilibrium profits, even when quality choice is endogenous and all costs of production are accounted for. There are a number of case studies that suggest that better product quality raises profitability, see [15][16]. Peters and Waterman, [11], study well managed U.S. companies and argue that the most profitable emphasize product and service quality. Changes in market share and changes in product quality are shown to be strongly related in [3]. Table 1, taken from [2], uses 1970's data from the Profit Impact of Marketing Strategies (PIMS) study which involved 1,200 businesses. It

\footnotetext{
${ }^{5}$ In contrast to this, Porter, see [12], takes the view supported by standard models of product differentiation. He argues that quality as such does not raise profits. Rather, he focuses on the role of product differentiation in reducing the extent of price competition. He highlights the importance of finding a "niche" so as to differentiate your product from the competition. He argues that product differentiation on the basis of quality creates a defensible competitive position and insulates a firm from competitive pressures in a way that competing solely on the basis of price and low costs could not achieve.

${ }^{6}$ Increasing quality is also seen as a means of reducing costs by reducing defects and material wastage as well as warranty claims and costs associated with recalls of products. See [9], [17], [19], and [5] for some interesting ideas on why such defects can end up being inordinately expensive. However, this cannot provide a reason why higher quality is more profitable. If faults are expensive, then profit maximizers will reduce faults until the marginal costs of reducing faults equals the benefit. Then firms which choose above the optimum quality levels make lower, not higher, profits than optimizing firms!
} 
shows that both the return on investment and profits as a percentage of sales revenue rise with quality. More recent data taken from [7] are presented in Table 2, which shows that the return on investment rises with quality, independent of how a firm's costs compare to its competitors'.

Third, the current paper suggests that the fixed costs of quality play a critical role in determining when free entry is consistent with the existence of profits and results in "natural oligopolies" and when it eliminates all profits. We see our results as complementary to those of Shaked and Sutton, see [13], who show that natural oligopolies can arise in a model of vertical product differentiation. ${ }^{7}$ They show that natural oligopoly arise if all consumers choose to buy from the highest quality firm when all firms price at their marginal cost of production (which depends on quality). These conditions are met if costs of production do not rise too fast with quality. Hence, in their model, if a large part of the cost of quality is fixed, then natural oligopolies will tend to occur. In our model, if all costs of production are fixed, natural oligopolies may or may not arise. Natural oligopolies also arise in Shaked and Sutton if there is low consumer heterogeneity as intense price competition drives out low quality firms. Of course, our model differs from theirs as there is no knowable consumer heterogeneity and we have a different interpretation of quality. Our results suggest that the shape of the fixed costs as a function of quality is also important in determining when natural oligopolies arise and when they do not.

We are aware of two papers that use a similar definition of quality to ours, but which have a very different focus. Price competition between an expert, who produces perfect quality and an non expert who is risky is studied in [1]. Thus, in effect they look at only the last stage of our model. ${ }^{8}$ In addition, they add differentiation a la Hotelling on the part of consumers. As a result, their model is much less tractable than ours. In [6] it is again assumed that one firm produces a perfect quality. In contrast to [1] however, the quality chosen by the other firm is endogenous and consumers differ in their probability of being satisfied by this low quality product. For any quality, there is a distribution of consumers over these probabilities. An increase in

\footnotetext{
${ }^{7}$ This work is nicely summarized in [21].

${ }^{8}$ Their main results are that if the quality of the low quality firm is very low then all consumers visit the low quality firm first and then the expert if they are not satisfied. If the quality of the low quality firm is high enough then some consumers visit the expert first, while if it is in between, then a simple form of a mixed strategy occurs where the expert randomizes between two prices and the other firm charges a single price.
} 
quality is seen as a shift of mass from low to high probabilities and much of the paper focuses on one such example. This setup has the advantage that payoffs are not necessarily discontinuous, as they are in our model, so that pure strategy equilibria can exist. However, it has the disadvantage that there are many ways for an increase in quality, even if one restricts attention to the given definition, to shift the demand curve. In his paper, Emons works with one such example. His main result is that the low quality firm does not choose to maximally differentiate itself from the firm with the perfect quality. This is not surprising; given that maximal differentiation would require the low quality firm to produce a quality of zero and earn no profits at all. It is well understood that even in the Hotelling model, minimal differentiation need not occur if costs of quality are not linear. If costs of quality are quadratic and consumers are distributed uniformly, there is maximal differentiation. See, for example, [4]. It is easy to construct examples of partial differentiation by altering the distribution of consumers. We choose to make all consumers as well as all firms ex ante identical in order to avoid such problems. This keeps the analysis simple and highlights the implications of a simple change in the model: namely the possibility of re-sampling. Also note that in contrast to [6] and [1] we are able to model the many firm case, as well as the prior entry decision. This allows us to address issues that [6] and [1] cannot.

The paper proceeds as follows. In Section 2 we look at the basic duopoly model. We show that a pure strategy equilibrium does not exist and construct the unique mixed strategy equilibrium. We find that the higher quality firm makes greater profits in equilibrium. We look at firms' quality choices in Section 3. We show that even though firms are ex ante identical, the only pure strategy equilibrium is asymmetric. In addition, we show that regardless of whether fixed costs of quality are convex or concave in quality, the higher quality firm makes greater profits. Sections 4 and 5 extend the results of the previous two sections to the $n$ firm case. We also look at entry decisions and find that when the fixed costs of quality are convex and start at the origin, free entry results in an infinite number of firms. However, when fixed costs of quality are concave, only a finite number of firms enter. In Section 6 we look at welfare while in Section 7 we allow for the presence of production costs and show that our result on higher profits for higher quality holds when, for example, marginal costs of production are linear in quality. Section 8 contains some concluding remarks. 


\section{The Model}

There are three stages to the game. In the first stage, firms decide whether to enter or not. Until Section 4 we assume there are two firms and so neglect this entry stage. In the second stage, firms choose the probability with which their product will satisfy the customer. This probability is interpreted as the quality of the product and represented by $q_{i}, i=1,2$. The fixed and sunk costs of producing a product of a given quality are incurred at this stage and are given by $C\left(q_{i}\right)$. In the third stage, the two firms compete in price. ${ }^{9}$ The payoff to the consumer when the product delivers is the same across the two firms, but the probability of delivery, $q$, differs between firms. We assume throughout the paper that there are a continuum of ex ante identical consumers with unit mass, who obtain the benefit $V$ from the product when it does deliver, and zero when it fails to satisfy. As consumers have some underlying heterogeneity which is unknown by both consumers and producers, one consumer may be satisfied by a product, while another may not. The source of this heterogeneity is left unspecified.

For given prices a consumer chooses which firm to buy from first. If that firm satisfies him, he goes no further. If it does not, he chooses whether to try the second firm or to quit. ${ }^{10}$ All participants are assumed to be risk neutral. We begin by solving the consumer's problem. We then use these results to solve for equilibrium in the last stage, which in turn forms the basis for solving for the equilibrium in the second stage and so on.

\subsection{The Consumer's Problem}

The consumer's problem is particularly simple. Assuming that the consumer chooses to be in the market, each of the identical consumers must choose which firm to buy from first and whether or not to visit another firm if the first firm visited does not deliver. The consumer chooses to visit a firm as long as it expects a positive payoff, that is as long as $q V-P$ is positive where $V$ is payoff to the consumer when the product delivers and $P$ is its price. Assuming that both firms are patronized, he chooses to visit the firm with

\footnotetext{
${ }^{9}$ Firms have zero marginal costs of production. Dropping the assumption that marginal costs are zero does not affect the flavor of the results as shown in Section 7 .

${ }^{10}$ Once a firm is visited, it is removed from the set of possible choices.
} 
the lower value of $\frac{P}{q}$ first. $^{11}$

\subsection{Profits and Prices in Duopoly}

In the last stage firms take their quality choices as given and essentially compete in prices. It turns out to be convenient to depict a firm's profit and pricing decisions in terms of its price quality ratio, rather than of prices alone, as this ratio determines the consumers' switching behavior. ${ }^{12}$

First, consider the case where $\frac{P_{L}}{q_{L}}<\frac{P_{H}}{q_{H}}$. In this event, the consumer first visits Firm $L$, the low quality firm, and pays $P_{L}$. With probability $\left(1-q_{L}\right)$ the consumer is not satisfied and subsequently visits the high quality firm, Firm $H$. Since there are a continuum of identical consumers, a fraction $\left(1-q_{L}\right)$ of them visit Firm $H$ as well as Firm $L$. On the other hand, if $\frac{P_{L}}{q_{L}}>$ $\frac{P_{H}}{q_{H}}$, the consumer visits Firm $H$ first and pays $P_{H}$. With probability $\left(1-q_{H}\right)$ the consumer is not satisfied and subsequently visits Firm $L$. Therefore a fraction $\left(1-q_{H}\right)$ of them visit Firm $L$ as well as $H .{ }^{13}$ At this stage it is useful to impose a tie-breaking rule. ${ }^{14}$

Assumption The lowest quality firm not previously visited is visited first in the event of a tie. In the two firm case, if both firms choose the same price quality ratio the consumer visits Firm $L$ first.

Hence, as long as $\frac{P_{H}}{q_{H}}<V$, the profits of Firm $H$ are given by:

$$
\pi_{H}\left(P_{L}, P_{H} \mid q_{H}, q_{L}\right)=\left\{\begin{array}{lll}
P_{H} & \text { if } & \frac{P_{H}}{q_{H}}<\frac{P_{L}}{q_{L}} \\
P_{H}\left(1-q_{L}\right) & \text { if } & \frac{P_{H}}{q_{H}} \geq \frac{P_{L}}{q_{L}}
\end{array} .\right.
$$

\footnotetext{
${ }^{11}$ This is a simple application of the "Buried Treasure Problem". A treasure worth $V$ could be buried in any of $N$ locations. Digging at location $i \operatorname{costs} P_{i}$ and the probability of finding the treasure in location $i$ is $q_{i}$. The solution to this problem involves choosing to dig where $\frac{q_{i} V-P_{i}}{q_{i}}$ is highest, ( where $\frac{P_{i}}{q_{i}}$ is lowest) until the treasure is found or all sites where $q_{i} V-P_{i}$ is positive have been visited. Generalizations of such problems are dealt with in $([22])$.

${ }^{12}$ Below we use price and this price quality ratio interchangeably.

${ }^{13}$ Note that we specify that the price is paid up front and not refunded if the product fails to deliver. If a firm guarantees "satisfaction or your money back", consumers simply compare the price of the guaranteed product to the price quality ratio of the unguaranteed product.

${ }^{14}$ This has no real effect on the problem but is a technical assumption ensuring that the support of the mixed strategies is a closed set.
} 
If $\frac{P_{H}}{q_{H}}>V$, profits are zero. The heavy line in Figure 1 depicts Firm $H^{\prime} s$ profits as a function of its price quality ratio. For price quality ratios below $\frac{P_{L}}{q_{L}}$, it has a slope of $q_{H},{ }^{15}$ while above $\frac{P_{L}}{q_{L}}$ its slope is $\left(1-q_{L}\right) q_{H}$. Firm $L$ 's profits can be analogously defined and are depicted in Figure 2.

\subsection{Best Responses}

Next, we construct best response functions for the two firms and show that their form precludes the existence of pure strategy equilibria. Notice that both segments of the firms' profit functions are monotonically increasing in each firm's own price. Therefore, a firm will maximize profits by choosing either the highest price quality ratio which will attract consumers to it first (the maximand of the first segment) or it will choose $V$ (the maximand of the second segment) and serve only those consumers who do not succeed in meeting their needs with their initial purchase. This behavior results in the best responses illustrated in Figure 3.

Let $\frac{P_{H}^{*}}{q_{H}}=\left(1-q_{L}\right) V$. It is defined so that Firm $H$ is indifferent between choosing the ratio $V$ and being visited second, and choosing the ratio $\frac{P_{H}^{*}}{q_{H}}$ and being visited first. In either case it will earn $\left(1-q_{L}\right) q_{H} V$. Consider Firm $H^{\prime} s$ best responses to various choices made by Firm $L$. If $\frac{P_{L}}{q_{L}}>\frac{P_{H}^{*}}{q_{H}}$, Firm $H$ will just undercut $\frac{P_{L}}{q_{L}}$ and earn more than it would by pricing at $V$. Whereas, if $\frac{P_{L}}{q_{L}} \leq \frac{P_{H}^{*}}{q_{H}}$, Firm $H$ will not undercut Firm $L$ because doing so would yield profits lower than those obtained by choosing $V$. Instead, Firm $H$ would choose $\frac{P_{H}}{q_{H}}=V$ and earn $\left(1-q_{L}\right) q_{H} V$. Define $\frac{P_{L}^{*}}{q_{L}}=\left(1-q_{H}\right) V$ and Firm $L^{\prime} s$ best responses in an analogous manner. It is clear that the best response functions do not intersect, and therefore there are no pure strategy equilibria in this game.

Proposition 1 There are no pure strategy equilibria when two firms compete in prices for given qualities.

Given Proposition 1 we turn our attention to mixed strategy equilibria. ${ }^{16}$

\footnotetext{
${ }^{15}$ This is because profits are drawn as a function of $\frac{P_{H}}{q_{H}}$ so that firm $H^{\prime} s$ profits are given by $\left(\frac{P_{H}}{q_{H}}\right) q_{H}$ and the slope of the profit function is $q_{H}$. Remember that quality is given at this stage so that price is being chosen for a given quality.

${ }^{16}$ One might suspect that a simple mixed strategy equilibrium exists, namely one where
} 


\subsection{Mixed Strategies}

The mixed strategy equilibrium we identify below has some interesting properties. First, the firms mix over the common support $\left[\frac{P_{H}^{*}}{q_{H}}, V\right]$. This makes sense as Firm $H$ will never want to price outside this support as it makes less than by pricing at $V$ and being visited second. For similar reasons, Firm $L$ will never want to price outside $\left[\frac{P_{L}^{*}}{q_{L}}, V\right]$. However, as $\frac{P_{H}^{*}}{q_{H}}>\frac{P_{L}^{*}}{q_{L}}$, Firm $L$ will never find it worthwhile to price below $\frac{P_{H}^{*}}{q_{H}}$ as Firm $H$ never will! Second, they have no holes in the distribution and no mass points, other than at $V$, where Firm $H$ has a mass point. Third, the mixed strategy of Firm $L$ is first order dominated by Firm $H^{\prime} s$ mix. Therefore, on average, Firm $H$ charges a higher price per unit of quality than Firm $L$. Note that the equilibrium profits of Firm $H$ are greater than those of Firm $L$ and these equilibrium profits are equal to what each firm would earn by pricing at $\frac{P_{H}^{*}}{q_{H}}$ and being visited first.

Proposition 2 In equilibrium the two firms choose the following mixed strategies expressed as cumulative density functions (CDF),

$$
\begin{aligned}
& F_{L}\left(\frac{P}{q}\right)=\frac{1}{q_{L}}-\frac{\left(1-q_{L}\right) V}{q_{L}}\left(\frac{P}{q}\right)^{-1} \text { for } \frac{P}{q} \in\left[\left(1-q_{L}\right) V, V\right] \\
& F_{H}\left(\frac{P}{q}\right)= \begin{cases}\frac{1}{q_{H}}-\frac{\left(1-q_{L}\right) V}{q_{H}}\left(\frac{P}{q}\right)^{-1} & \text { for } \frac{P}{q} \in\left[\left(1-q_{L}\right) V, V\right) \\
1 & \text { for } \frac{P}{q}=V .\end{cases}
\end{aligned}
$$

and earn respective equilibrium profits of ${ }^{17}$

$$
\begin{aligned}
& \pi_{H}^{E}=\left(1-q_{L}\right) q_{H} V \\
& \pi_{L}^{E}=\left(1-q_{L}\right) q_{L} V .
\end{aligned}
$$

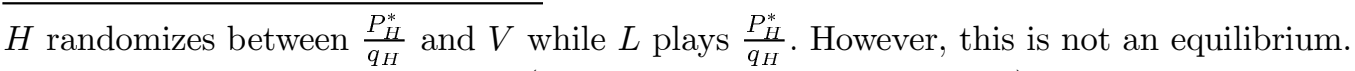
If $L$ is assumed to be visited first (or if firms are visited randomly) in the event of a tie, then $H$ prefers $V$ to $\frac{P_{H}^{*}}{q_{H}}$ so that this is not an equilibrium. If $H$ is visited first in the event of a tie then $L$ prefers to charge slightly less than $\frac{P_{H}^{*}}{q_{H}}$ ensuring he is visited first so that this is not an equilibrium either.

${ }^{17}$ Again, if a firm guarantees "satisfaction or your money back" the consumers compare the price of the guaranteed product to the price quality ratio of the unguaranteed product. However, the firm that offers the guarantee will use the same mixed strategy to choose its price (rather than its price quality ratio) and earn the same equilibrium profits. 
It is easy to verify that this is indeed an equilibrium by confirming the following. ${ }^{18}$ First, that this is a CDF as it is increasing and takes the value of zero at the bottom and of unity at the top of its support. Second, when one firm mixes according to its given distribution, the profits of the other are independent of which price quality ratio it chooses from the support. Third, neither firm can improve its profits by choosing a ratio outside the support. It is also easy to verify that this is a special case of the $n$-firm equilibrium strategies established in Section 6.

Note that the tie breaking assumption made earlier is not critical. If instead we assumed that Firm $H$ was visited first, then Firm $L$ would no longer choose a ratio of $V$. Since Firm $H$ has a mass point at $V$ Firm $L$ could do better by charging slightly less than $V$. However, Firm $L$ does not have a mass point at $V$ so this does not affect the equilibrium profits of Firm $H$. Thus, the above equilibrium works with the proviso that Firm $L$ only mixes over the half open interval $\left[\frac{P_{H}^{*}}{q_{H}}, V\right)$.

Notice that the total profits of the firm with the lower quality are independent of the quality chosen by the higher quality firm, as long as their quality ranking is unchanged. This ends up playing a crucial role below. Now we turn to the issue of how quality is chosen in stage two.

\section{Choosing Quality}

Firms realize that their choice of quality will affect their profits in the subsequent stage and they incorporate this information into their decision making in the prior stage. The net profit function for Firm $i$, given that its rival chooses the quality $q_{-i}$, is a composite function denoted by $\Pi_{i}\left(q_{i}, q_{-i}\right)$ where: ${ }^{19}$

$$
\Pi_{i}\left(q_{i}, q_{-i}\right)=\left\{\begin{array}{c}
\left(1-q_{i}\right) q_{i} V-C\left(q_{i}\right) \text { for } q_{i} \leq q_{-i} \\
\left(1-q_{-i}\right) q_{i} V-C\left(q_{i}\right) \text { for } q_{i} \geq q_{-i} .
\end{array}\right.
$$

Note that the firm's profit function is continuous in $q_{i}$ for any $q_{-i}$ chosen by its competitor. Firms choose their quality to maximize their total profits, given the quality chosen by their competitor. This results in best responses in quality space, which we define below.

\footnotetext{
${ }^{18}$ It can be shown that with two firms this is the unique equilibrium. As we cannot show this with $n$ firms, we do not emphasize it.

${ }^{19}$ Note that $\Pi$ denotes the profits net of fixed costs of quality while $\pi$ excludes these costs.
} 


\subsection{Quality Choices}

It is apparent from (1) that the second segment of this composite profit function shifts downwards as the competitor's quality rises. Thus, we would suspect that for high values of the competitor's quality, the peak of Firm $i^{\prime} s$ profit function occurs along the first segment of the composite function, while for low values of the competitor's quality, the peak of Firm $i^{\prime} s$ profit function occurs along the second segment of the composite function. At some intermediate value of the competitors quality, denoted by $\widetilde{q}$, the two peaks yield the same level of profits. Consequently, the best response of Firm $i$ in quality space jumps at $\widetilde{q}$. We show that this jump eliminates the possibility of a symmetric pure strategy equilibrium where both firms choose the same quality. However, there are two asymmetric pure strategy equilibria that are mirror images of each other.

Let $\underline{q}_{L}$ denote the level of $q$ that maximizes profits along the first part of the function. Let $\Pi_{L}\left(\underline{q}_{L}\right)=\pi_{L}\left(\underline{q}_{L}\right)-C\left(\underline{q}_{L}\right)$ denote this level of profits which we assume to be positive. Hence, at $\underline{q}_{L}$ the first order condition of $\pi_{L}(\underline{q})$ $-C\left(q_{L}\right)$ holds, ${ }^{20}$

$$
\left(1-2 \underline{q}_{L}\right) V-C^{\prime}\left(\underline{q}_{L}\right)=0 .
$$

There are several properties which should be noted at this time. $\pi_{L}(q)$ attains its maximum at $q=1 / 2$, and therefore the maximum of $\pi_{L}(q)-C(q)$ must occur at $\underline{q}_{L}<1 / 2$. When $q_{i}=q_{-i}=\underline{q}_{L}$, the switch from the first segment to the second segment of the profit function of Firm $i$ occurs at $\underline{q}_{L}$. At this point, Firm $i^{\prime} s$ profits are increasing in its own quality as shown by Lemma 1 in Appendix 1. By increasing its quality beyond $\underline{q}_{L}$, Firm $i$ becomes the high quality producer and earns higher profits on the second segment of the composite profit function. This is the reason why the high quality firm makes greater profits in equilibrium than the low quality firm which chooses $\underline{q}_{L}$.

\subsubsection{Concave Costs}

When cost are concave, the second segment of Firm $i^{\prime} s$ profit function, $\Pi_{H}\left(q, q_{-i}\right)$, is convex in its own quality, as depicted in Figure 4. Hence, the peak of this segment occurs at $q=1$ and $\tilde{q}$ is defined by,

$$
\Pi_{H}(1, \tilde{q})=\Pi_{L}\left(\underline{q}_{L}\right) .
$$

\footnotetext{
${ }^{20}$ We assume throughout that that $C^{\prime}() \geq$.0 .
} 
Lemma 2 in Appendix 1 confirms that $\underline{q}_{L}<\tilde{q}<1$ so that the jump in the best response functions eliminates symmetric pure strategy equilibria.

The form of the best responses is now clear. A firm chooses a quality of $\underline{q}_{L}$ if its opponent chooses a quality $q_{-i} \geq \tilde{q}$, and chooses a quality of 1 for $q_{-i} \leq \tilde{q}$. Thus there are two equilibria at points $A$ and $B$ as depicted in Figure 5. They are mirror images of one another where one firm chooses $\underline{q}_{L}$ and the other chooses $q=1$. Our results so far are summarized below.

Proposition 3 When costs of quality are concave and non decreasing in $q$ there are two pure strategy equilibria, which are mirror images of one another, where one firm chooses $\underline{q}_{L}$ and the other chooses $q=1$. In equilibrium, the high quality firm makes greater profits than the low quality firm.

We now turn to the case with convex costs of quality.

\subsubsection{Convex Costs}

When $C\left(q_{i}\right)$ is convex the second segment of the profit function is concave. This is depicted in Figure 6 which is analogous to Figure 4. As a consequence, if the firm chooses to operate on this second segment, it need not be best off choosing a quality of 1 . Let $q_{H}\left(q_{L}\right)$ denote the profit maximizing choice of quality in this case. ${ }^{21}$ This best response is implicitly defined by:

$$
\left(1-q_{L}\right) V-C^{\prime}\left(q_{H}\left(q_{L}\right)\right)=0
$$

provided that $\left(1-q_{L}\right) V-C^{\prime}(1)<0 .{ }^{22}$ Note that $q_{H}\left(q_{L}\right)$ is weakly downward sloping. Let the maximized profits along $q_{H}\left(q_{L}\right)$ be denoted by $\Pi_{H}\left(q_{H}\left(q_{L}\right), q_{L}\right)$. Then $\Pi_{H}\left(q_{H}\left(\underline{q}_{L}\right), \underline{q}_{L}\right)$ denotes the profits associated with choosing quality optimally when Firm $L$ chooses $\underline{q}_{L}$.

In this case it is easy to see that there is a pure strategy equilibrium. The best response of a firm will be either $q_{H}\left(q_{L}\right)$ or $\underline{q}_{L}$, depending on which gives greater profits. We show that $q_{H}\left(q_{L}\right)$ is chosen if the other firm's quality choice is low enough and $\underline{q}_{L}$ is chosen if the other firm chooses quality above a critical level denoted by $\tilde{q}$. In the convex case $\tilde{q}$ is implicitly defined by:

$$
\Pi_{H}\left(q_{H}(\tilde{q}), \tilde{q}\right)=\Pi_{L}\left(\underline{q}_{L}\right) .
$$

\footnotetext{
${ }^{21}$ We assume that as $q$ goes to zero, the slope of $C($.$) also goes to zero. This ensures$ that a quality choice of zero is not optimal.

${ }^{22}$ Of course, if $\left(1-q_{L}\right) V-C^{\prime}(1) \geq 0$, then a corner solution occurs and $q_{H}\left(q_{L}\right)=1$.
} 
Let $q_{L}^{c}$ denote the value of $q_{L}$ where $q_{H}\left(q_{L}\right)$ intersects the 45 degree line. That is:

$$
q_{H}\left(q_{L}^{c}\right)=q_{L}^{c}
$$

In Lemma 3 in Appendix 1, it is shown that $\underline{q}_{L}<\tilde{q}<q_{L}^{c}<1$ where $\tilde{q}$ and $q_{L}^{c}$ are defined in (5) and (6) respectively.

The form of the best response functions and the equilibrium is now clear. A firm chooses a quality of $q_{L}$ if its opponent chooses a quality $q_{-i} \geq \tilde{q}$ and chooses a quality of $q_{H}\left(q_{L}\right)$ if $q_{-i} \leq \tilde{q}$. The best responses look much like those in the case of concave costs. The only difference is that with convex cost they can be downward sloping for low $q$ choices by the opponent.

The best responses are drawn in Figure 7. Two asymmetric pure strategy equilibria can be seen to exist as a consequence of Lemma 3. These are mirror images of one another, at points $A$ and $B$. In equilibrium, one firm chooses $\underline{q}_{L}$ and the other chooses $q_{H}\left(\underline{q}_{L}\right)$. Note that once again the high quality firm always makes greater profits in equilibrium than the low quality one. ${ }^{23}$ Our results so far are summarized below.

Proposition 4 When costs of quality are convex in $q$ there are two pure strategy equilibria. These are mirror images of one another, where one firm chooses $\underline{q}_{L}$ and the other chooses $q_{H}\left(\underline{q}_{L}\right)$. In equilibrium, the high quality firm makes greater profits than the low quality one.

What if choices were sequential? Here again it is worth considering the concave costs of quality separately from the convex case. In the concave case the first mover has to essentially choose between the two equilibria $A$ and $B$ in Figure 5. Of course, he chooses to be the high quality producer. Hence, the Stackelberg equilibrium is a subset of the Nash equilibria.

With convex costs of quality, the first mover (whose quality is on the vertical axis) can choose $A$ to be the equilibrium as the best response function of the opponent is flat if the first mover chooses $A$ as depicted in Figure 7. As profits are higher at $A$ for the firm labelled $H$ than at the points $K$ and $L$ (where profits are equal) they exceed profits along the downward sloping

\footnotetext{
${ }^{23}$ There are other equilibria in mixed strategies. For example, it is easy to verify that with convex costs, one firm mixing over the two points $\underline{q}_{L}$ and $q_{H}(\tilde{q})$ and the other choosing $\tilde{q}$ constitutes a mixed strategy equilibrium. We suspect that there is also at least one symmetric mixed strategy equilibrium since the game itself is symmetric. We focus only on pure strategy equilibria in quality space in order to be able to interpret quality as we do as the known probability of being satisfied.
} 
part of the opponents best response function. Hence, the Stackelberg point for the firm which is the leader remains at $A$.

Proposition 5 The firm which moves first will produce a higher quality and earn higher profits whether costs of quality are concave or convex.

\section{Extension to Many Firms}

So far we have assumed that there are only two firms in the market. How are the results affected by the presence of more firms? What is the equilibrium under free entry? We turn to these questions in this and the next section.

As before,

$$
\pi_{i}\left(\frac{P_{i}}{q_{i}}\right)=\left\{\begin{array}{lr}
P_{i} & \text { for } \frac{P_{i}}{q_{i}}<\min _{j \neq i} \frac{P_{j}}{q_{j}} \\
P_{i} \prod_{j \in L\left(i, \frac{P}{q}\right)}\left(1-q_{j}\right) & \text { for } \frac{P_{i}}{q_{i}} \geq \min _{j \neq i} \frac{P_{j}}{q_{j}}
\end{array}\right.
$$

where $L\left(i, \frac{P}{q}\right)$ is the set of firms that would be visited before Firm $i$, given the price quality ratios chosen by all firms are represented by the vector $\frac{P}{q}$. Recall that in the event of a tie, the firm with lowest quality among those which are tied is visited first. As before each firm's profits jump down every time its price quality ratio surpasses that of another firm.

\subsection{Pure Strategies}

Can there be a pure strategy equilibrium to this game? No. The proof consists of assuming that such an equilibrium exists and showing that this leads to a contradiction. Suppose that there were a pure strategy equilibrium. Consider the firm with the lowest price quality ratio, Firm $k$. Firm $k^{\prime} s$ profits are increasing in its own price at the candidate equilibrium if it has the lowest price quality ratio. Hence it will wish to raise its price. In the event of a tie, let $k$ be the firm with the highest quality among the firms with the lowest price quality ratio. Then Firm $k$ is best off reducing its price by a bit and getting all consumers to visit it first. In fact, for any tie breaking rule, it is always in the interest of some firm to slightly undercut the others. ${ }^{24}$

\footnotetext{
${ }^{24}$ If the split is equal, then it is in the interest of all tied firms to slightly undercut each other.
} 
Proposition 6 There is no pure strategy equilibrium when $n$ firms compete in prices for given qualities.

\subsection{Mixed Strategy Equilibrium}

Here we look for mixed strategy equilibria. Following the method employed in the two firm case, we must characterize the expected profits of Firm $i$ when all other firms, $j \neq i$, use mixed strategies $F_{j}($.$) . First look at what$ occurs when there is only one rival firm, call it $j$. For each price quality ratio chosen by Firm $i$, either Firm $j$ chooses a price quality ratio weakly below that chosen by Firm $i$ or it chooses a price quality ratio above that chosen by Firm $i$. The former event occurs with probability $F_{j}\left(\frac{P_{i}}{q_{i}}\right)$ in which case Firm $j$ is visited before Firm $i$ so that Firm $i$ earns $\left(1-q_{j}\right) P_{i}$. The latter event occurs with probability $\left[1-F_{j}\left(\frac{P_{i}}{q_{i}}\right)\right]$. In this event Firm $i$ is visited before Firm $j$ and Firm $i$ earns $P_{i}$. Hence:

$$
E\left[\pi_{i}\left(\frac{P_{i}}{q_{i}}, F_{j}(.)\right)\right]=P_{i}\left[F_{j}\left(\frac{P_{i}}{q_{i}}\right)\left(1-q_{j}\right)+\left[1-F_{j}\left(\frac{P_{i}}{q_{i}}\right)\right]\right] .
$$

In general, the expected profits of Firm $i$, when there are $n$ firms competing, are given by:

$$
E\left[\pi_{i}\left(\left(\frac{P_{i}}{q_{i}}\right), F_{-i}(.)\right)\right]=P_{i} \prod_{j \neq i}^{n}\left[1-F_{j}\left(\frac{P_{i}}{q_{i}}\right) q_{j}\right]=K_{i}
$$

where $K_{i}$ denotes the equilibrium level of profits for Firm $i$, and $F_{-i}($.$) de-$ notes the vector of cumulative distribution functions for all firms but Firm $i$. See Lemma 4 in Appendix 2 for a proof.

We now postulate a form for all these cumulative distribution functions and then show that these distribution functions constitute an equilibrium. Let $q_{0}=0$ and number the firms so that higher quality firms have a higher index, that is, $0=q_{0} \leq q_{1} \leq q_{2} \leq . . \leq q_{n}$. Define the numbers:

$$
R_{i}=\frac{\prod_{t=i}^{n-1}\left(1-q_{t}\right)}{\left(1-q_{i}\right)^{n-i}} V \text { for } i=0, . . n-1 .
$$

Note that $R_{0}=V \prod_{t=1}^{n-1}\left(1-q_{t}\right)$ and $R_{n-1}=V$ and that by Lemma 5 in Appendix 2, $R_{i}<R_{i+1}$. All firms will have $R_{0}$ as the lower bound for the 
support of their distributions. As the price quality ratio rises, firms drop out successively on the basis of their quality. All firms compete in the interval $\left[R_{0}, R_{1}\right]$, then Firm 1 drops out and the remaining firms compete over the interval $\left[R_{1}, R_{2}\right]$. More generally, Firm $i$ mixes over the range $\left[R_{0}, R_{i}\right]$. Only the two highest quality firms compete in the region $\left[R_{n-2}, V\right]$. This is depicted in Figure 8. Note that $\frac{P_{H}^{*}}{q_{H}}$ in the two-firm problem is a special case of $R_{0}$. The highest quality firm is indifferent between being visited first when it chooses $R_{0}$ and being visited last when it chooses $V$. In either case it receives $V q_{n} \prod_{t=1}^{n-1}\left(1-q_{t}\right)$, which defines $q_{n} R_{0}$. Note that this also suggests that the equilibrium profits of Firm $i$ will be $q_{i} R_{0}$, those it gets when pricing at the lower bound of its distribution and all consumers visit it first.

We must define these distribution functions for each Firm $j$. For Firm $j$, $F_{j}()=$.1 for price quality ratios above $R_{j}$. In the region between $R_{i-1}$ and $R_{i}$ with $j>i$,

$$
F_{j}\left(\frac{P}{q}\right)=\frac{1-\left[V\left[\frac{P}{q}\right]^{-1} \prod_{t=i}^{n-1}\left(1-q_{t}\right)\right]^{\frac{1}{n-i}}}{q_{j}}
$$

This defines the distribution function used by Firm $j$ in the interval $\left[R_{i-1}, R_{i}\right]$ where firms $i$ through $n$ are competing, and firms 1,2,i-1 have dropped out.

Note that from equation (8), the cumulative distribution function of a higher quality firm lies weakly below that of a firm with a lower quality, and that the inequality is strict in the region where at least one of the two firms is active. In other words, $F_{j}($.$) for Firm j$ which is active in a particular interval lies above that for any firm with a higher index. ${ }^{25}$ This is also depicted in Figure 8.

Also, note that the lower bound for all firms is common at $R_{0}$ (see Lemma 6 in Appendix 2) and that $F_{i}($.$) is a continuous function, { }^{26}$ except for $F_{n}($. which has a mass point at $V$ (see Lemma 7 in Appendix 2).

Proposition 7 Let there be $n$ firms, each producing a quality $q_{j}$, where $0=$ $q_{0} \leq q_{1} \leq q_{2} \leq . . \leq q_{n}$. Then, a mixed strategy equilibrium is given by each

\footnotetext{
${ }^{25}$ Hence the point where it hits unity lies below that of a firm with a higher index.

${ }^{26}$ Though $F_{j}$ need not be differentiable at the point where any firm drops out, that is it can have a kink at $R^{i}$ for $i<j$.
} 
firm mixing according to the cumulative distribution function, $F_{j}\left(\frac{p}{q}\right)$ where:

$$
F_{j}\left(\frac{P}{q}\right)=\left\{\begin{array}{cc}
\frac{1-\left[V\left[\frac{P}{q}\right]^{-1} \prod_{t=i}^{n-1}\left(1-q_{t}\right)\right]^{\frac{1}{n-i}}}{q_{j}} & \text { for } \frac{P}{q} \in\left[R_{i-1}, R_{i}\right] \text { and } i \leq j \\
1 & \text { for } \frac{P}{q}>R_{j}
\end{array}\right.
$$

Each firm makes equilibrium profits of $\pi_{j}^{E}$ where:

$$
\pi_{j}^{E}=V q_{j} \prod_{t=1}^{n-1}\left(1-q_{t}\right)
$$

The proof consists of checking that $F_{j}\left(\frac{P}{q}\right)$ is a distribution function and that Firm $j$ obtains $\pi_{j}^{E}$ as profits in the support of its distribution while profits elsewhere are no higher than $\pi_{j}^{E}$. This is done in Appendix 2.

\section{Quality Choices and Free Entry}

In this section we look at what kinds of equilibria could occur when firms choose whether to enter and then choose quality. First, we look at the quality choices of a given number of firms and then proceed to the entry decision, which occurs at the previous stage. The net expected profits of a firm with quality $q_{i}$ are given by,

$$
\Pi_{i}\left(q_{i}, q_{-i}\right)=V q_{i} \prod_{t=1}^{n-1}\left(1-q_{t}\right)-C\left(q_{i}\right) .
$$

It is convenient to define $Z_{i}=\prod_{\substack{t=1 \\ t \neq i}}^{n-1}\left(1-q_{t}\right)$ and rewrite $(9)$ in as,

$$
\Pi_{i}\left(q_{i}, q_{-i}\right)=V\left(1-q_{i}\right) q_{i} Z_{i}-C\left(q_{i}\right) \text { for } i \neq n .
$$

Notice that $Z_{i}$ does not depend on $q_{i}$, that $Z_{i}<Z_{i+1}$, because $\left(1-q_{i+1}\right)<$ $\left(1-q_{i}\right)$, and that the first term of Firm $n^{\prime} s$ profit function differs importantly from other firms'. The first term of Firm $n^{\prime} s$ profit function is linear in its own quality choice whereas, the first terms of the remaining firms' profit functions are quadratic in their own quality choices.

In equilibrium, all but Firm $n$ choose qualities to maximize profits according to the first order conditions,

$$
\left(1-2 q_{i}^{*}\right) V Z_{i}-C^{\prime}\left(q_{i}^{*}\right)=0
$$


while Firm $n^{\prime} s$ optimization depends on the nature of the cost of quality.

If costs of quality are convex Firm $n$ chooses $q_{n}^{*}$ to satisfy,

$$
V \prod_{t=1}^{n-1}\left(1-q_{t}\right)-C^{\prime}\left(q_{n}^{*}\right)=0
$$

If costs of quality are concave, profits are maximized at a corner. Assuming that the maximized value of profits is positive, then,

$$
q_{n}^{*}=1 .
$$

It is easy to see from the above that there could be at least two kinds of equilibria. In the first "almost symmetric" case, all but the highest quality firm choose the same quality. In the second, "asymmetric" case, all firms choose different qualities. While it is easy to construct almost symmetric equilibria, asymmetric equilibria require very special cost structures. In Appendix 3, we work out example with $C(q)=q^{2}$ and shown why the conditions for the existence of an asymmetric equilibrium in quality are quite restrictive. For this reason we have focused on the almost symmetric equilibrium below.

\subsection{The Almost Symmetric Case}

Consider an almost symmetric equilibrium where all but Firm $n$ choose the same quality. We can then drop the subscript $i$ from the $q_{i}^{*}$ in (10) and rewrite it as,

$$
V\left(1-2 q^{*}\right)\left(1-q^{*}\right)^{n-2}=C^{\prime}\left(q^{*}\right) .
$$

If costs of quality are convex, (11) can be rewritten as,

$$
V\left(1-q^{*}\right)^{n-1}-C^{\prime}\left(q_{n}^{*}\right)=0 .
$$

Note that profits of Firm $n$ again exceed those of the other firms ${ }^{27}$. Free entry thus implies zero profits for all but the highest quality firm in this almost symmetric equilibrium so that,

$$
V q^{*}\left(1-q^{*}\right)^{n-1}-C\left(q^{*}\right)=0 .
$$

Hence, the three equations, (13), (14) or (12), and (15) characterize the free entry equilibrium of the almost symmetric form.

\footnotetext{
${ }^{27}$ This follows from the definition of profits in (9) and the observation that $q_{n}^{*}$ exceeds $q^{*}$ since they are defined respectively by (13) and (14) above and as $\frac{\left(1-2 q^{*}\right)}{\left(1-q^{*}\right)}<1$.
} 
Rewriting (13), (14) and (15) gives,

$$
\begin{aligned}
V\left(1-q^{*}\right)^{n-1} & =C^{\prime}\left(q^{*}\right) \frac{\left(1-q^{*}\right)}{\left(1-2 q^{*}\right)} \\
V\left(1-q^{*}\right)^{n-1} & =C^{\prime}\left(q_{n}^{*}\right) \\
V\left(1-q^{*}\right)^{n^{*}-1} & =\frac{C\left(q^{*}\right)}{q^{*}} .
\end{aligned}
$$

The first of these three equations defines the quality choice for the lower quality firms, $q^{*}$, the second that of the high quality firm, $q_{n}^{*}$, while the last determines the number of firms, $n^{*}$. Figure 9 depicts these curves as functions of $q$ when cost of quality are convex.

Note that $V(1-q)^{n-1}$ gives a downward sloping curve which starts at $V$ on the vertical axis and reaches zero at $q=1$. The curve $C^{\prime}(q)$ starts at zero and is increasing in $q$ while $C^{\prime}(q) \frac{(1-q)}{(1-2 q)}$ starts at the same point as $C^{\prime}($. but lies above it and asymptotes to infinity at $q=1 / 2$. For a given $n, q^{*}(n)$ is given by the intersection of $V(1-q)^{n-1}$ and $C^{\prime}(q) \frac{(1-q)}{(1-2 q)}$, while $q_{n}^{*}(n)$ is given by moving horizontally over to $C^{\prime}($.$) . At q^{*}(n)$ each firm earns revenues of $\left(1-q^{*}(n)\right)^{n-1} q^{*}(n) V$, the area of the relevant rectangle in Figure 9, and incurs fixed costs of $C\left(q^{*}(n)\right)$, which is the area under $C^{\prime}($.$) up till q^{*}(n)$. As is evident this is positive. As $n$ rises, $V\left(1-q^{*}\right)^{n-1}$ bows in to the origin so that both $q^{*}(n)$ and $q_{n}^{*}(n)$ fall. However, as profits remain positive for all $n$, there are an infinite number of firms in the free entry equilibrium.

The careful reader might ask what ensures that there is no entry at the upper end of the quality spectrum. If this did occur the entering firm could look forward to getting

$$
\left(1-q^{*}(n)\right)^{n-1}\left(1-q_{n}^{*}(n)\right) V q_{n+1}-C\left(q_{n+1}\right)
$$

and the distribution for all firms will begin at a lower point namely at $(1-$ $\left.q^{*}(n)\right)^{n-1}\left(1-q_{n}^{*}(n)\right)$. But recall that $\left(1-q^{*}(n)\right)^{n-1} V=\frac{C\left(q_{n}^{*}\right)}{q_{n}^{*}}$. Since

$$
\left(1-q^{*}(n)\right)^{n-1}\left(1-q_{n}^{*}(n)\right) V<\left(1-q^{*}(n)\right)^{n-1} V=\frac{C\left(q_{n}^{*}\right)}{q_{n}^{*}}<\frac{C\left(q_{n+1}\right)}{q_{n+1}}
$$

Firm $n+1$ must be making losses! This proves that there can be no entry from the top if entry from the bottom is unprofitable.

If costs are concave, then the curve $C^{\prime}(q)$ starts at a positive value and is decreasing in $q$ as depicted in Figure 10. Again, the curve $C^{\prime}(q) \frac{(1-q)}{(1-2 q)}$ 
starts at the same point as $C^{\prime}(q)$ but lies above it and asymptotes to infinity at $q=1 / 2$. Thus it cannot be monotonic in $q$ and is depicted as having a single turning point. For a given $n, q^{*}(n)$ is given by the intersection of $(1-q)^{n-1} V$ and $C^{\prime}(q) \frac{(1-q)}{(1-2 q)}$, while $q_{n}^{*}(n)=1$. At $q^{*}(n)$ each firm earns revenues of $\left(1-q^{*}(n)\right)^{n-1} q^{*}(n) V$ and incurs fixed costs of $C\left(q^{*}(n)\right)$. Entry causes $\left(1-q^{*}\right)^{n-1} V$ to bow toward the origin and will continue until net profits are driven to zero, when $\left(1-q^{*}(n)\right)^{n-1} V=\frac{C\left(q^{*}(n)\right)}{q^{*}(n)}$. As illustrated by point $\mathrm{A}, n^{*}$ satisfies these conditions for a free entry equilibrium. Note that Firm $n^{\prime} s$ revenues exceed its fixed costs since $\left(1-q^{*}\right)^{n^{*}-1} V q>\frac{C(q)}{q}$ when $q=1$, as depicted in Figure 10 .

\subsection{The Asymmetric Case}

There remains the possibility of asymmetric equilibria where all firms choose different qualities. If costs of quality are concave, Firm $n$ chooses a quality of unity as in the almost symmetric case. For this to be an equilibrium it must satisfy all of the $n-1$ first order conditions implied by (10) and Firm $n^{\prime} s$ first order condition from (11). This is only possible given a very special cost of quality function.

Again, free entry would define the equilibrium number of firms. As the equilibrium profits of firms are increasing in quality, the profits of the firm with the lowest quality would have to be zero. However, if marginal costs of quality at zero are zero, then firms would keep on entering as profits would be bounded away from zero. Hence, as before, if costs of quality are convex, an infinite number of firms enter under free entry. If costs of quality are concave, then free entry requires only that the lowest quality firm make zero profits or,

$$
q_{1} V \prod_{t=1}^{n-1}\left(1-q_{t}\right)-C\left(q_{1}\right)=0 .
$$

Such equilibria need not exist as the equations defining them, (10) (11) and (19) are highly non linear. An example with convex costs, $C(q)=q^{2}$ is worked out in Appendix 3 where this is illustrated.

\section{Welfare}

In this section we ask whether the qualities chosen by firms are socially optimal. As usual, social welfare equals the sum of consumer and producer 
surplus as we assume there is a numeraire good and all profits are returned to consumers in a lump sum. Since prices paid enter negatively into consumer surplus, but positively into producer surplus, they cancel out in the social welfare calculations. Recall that as demand is completely inelastic, there is no distortion caused by the existence of market power, for given quality levels. If prices are high, firms get a greater share of the social surplus than if prices are low, but the sum of consumer and producer surplus is constant. However, the level of the social surplus itself could be sub-optimal if the quality choices of the firms differ from those a social planner would make.

The simplest way to calculate welfare is to note that as consumers who are not satisfied by their purchases from one firm always choose to visit another, welfare is just $V$ times the probability that consumers are satisfied by some firm, less the fixed cost of the quality chosen. This probability can be expressed as unity, less the probability that consumers are not satisfied by either firm, so that welfare is,

$$
\begin{aligned}
W & =\left(1-\left(1-q_{L}\right)\left(1-q_{H}\right)\right) V-C\left(q_{L}\right)-C\left(q_{H}\right) \\
& =\left[q_{H}+q_{L}-q_{H} q_{L}\right] V-C\left(q_{L}\right)-C\left(q_{H}\right)
\end{aligned}
$$

when there are two firms. More generally with $n$ firms,

$$
W=\left(1-\prod_{i=1}^{n}\left(1-q_{i}\right)\right) V-\sum_{i=1}^{n} C\left(q_{i}\right) \text {. }
$$

This is a particularly simple symmetric form. Consider the two firm case. As demand is completely inelastic, there is no monopoly distortion and no dead weight loss of pricing above marginal costs. However, if quality is not perfect, $q_{i} \neq 1$, then the utility of $V$ is not obtained by visiting Firm $i$, but instead $q_{i} V$ is obtained. If the first try fails, a second chance to get $V$ can be obtained by visiting the other firm and this gives utility $\left(1-q_{i}\right) q_{-i} V$. However, each chance at getting $V$ comes at a cost of $C(q)$ so that it may be socially optimal to settle for only one try rather than two. If costs of quality are convex, it is expensive to have high quality so that it is best to opt for two chances at $V$ and choose equal levels of $q$ (due to the symmetry of the two firms) and a positive probability of not getting $V$. If costs of quality are concave, it is not expensive to have perfect quality so that it is best to be sure to get $V$ on the first try. In this case the second chance is worthless. This is what we show more formally below. 
It is useful to look at the pseudo best responses of the social planner. In the two firm case, these are defined as the choice of $q_{H}$ (or alternatively, $q_{L}$ ) which maximize social welfare for a given level of $q_{L}$ (or alternatively $q_{H}$ ). This is preferable to relying on first order conditions alone since welfare is convex in quality when costs of quality are concave so that the maximum occurs at a corner. Thus, with concave costs of quality, welfare is maximized at $q_{H}=1$ if $V\left(1-q_{L}\right)-C(1) \geq 0$ and at $q_{H}=0$ if $V\left(1-q_{L}\right)-C(1) \leq 0$. Hence $q_{H}=1$ for $q_{L}$ close to zero and $q_{H}=0$ for $q_{L}$ close to unity with a switch at $V\left(1-q_{L}\right)=C(1)$. Thus, the intersection of the pseudo best responses occurs at the points $(0,1)$ and $(1,0)$. It is optimal to have only one firm in the market producing perfect quality. This makes sense as this policy gives a utility of $V$ at minimum cost. Similarly, with $n$ firms, welfare is maximized at $q_{j}=1$ if $\underset{i=1, i \neq j}{V}\left(1-q_{i}\right)-C(1) \geq 0$ and at $q_{j}=0$ if $\underset{i=1, i \neq j}{n}\left(1-q_{i}\right)-C(1) \leq 0$. Again, it is optimal to have only one firm producing perfect quality.

With two firms and convex costs of quality, it is optimal to allow a second firm so that consumers get a second chance to get $V$. In this way total utility, while short of $V$, is as high as possible. More formally, consider the pseudo best responses. As welfare is concave in quality these pseudo best responses in the two-firm case are defined by the first order conditions:

$$
\frac{\partial W}{\partial q_{i}}=\left(1-q_{-i}\right) V-C^{\prime}\left(q_{i}\right)=0
$$

It is easy to see that this looks like the first order condition for Firm $H$ which defined $q_{H}\left(q_{L}\right)$ earlier. The symmetry of the first order conditions requires that the socially optimal policy is to choose the same quality level for both firms. Similarly, with $n$ firms, welfare is maximized at

$$
\prod_{i=1, i \neq j}^{n}\left(1-q_{i}\right) V-C^{\prime}\left(q_{j}\right)=0
$$

and it is optimal to have all firms producing the same quality.

Proposition 8 If costs of quality are concave it is optimal to have only one firm producing perfect quality. If costs of quality are convex it is optimal to have all firms producing the same quality. 
It is also worth comparing the choices of a monopolist with the socially optimal ones when there are two firms. A monopolist will always charge a price of $V q$ as this is the common reservation price. Hence he will choose $q$ to maximize $V q-C(q)$. With concave costs of quality a monopolist sets $q=1$, the socially optimal level, assuming that it is optimal to produce at all. If costs of quality are convex, a quality level of $q_{m}$, which satisfies $V=C^{\prime}\left(q_{m}\right)$, is chosen by the monopolist. Comparing this with the choices under duopoly shows the following.

Proposition 9 With concave costs of quality a monopolist chooses the socially optimal level of quality. If costs of quality are convex, he chooses a quality level which exceeds that chosen by the high quality firm in the duopoly, as well as the socially optimal level. If the monopolist is allowed to control more than one firm, then the socially optimal quality is chosen.

This should not be surprising as the monopolist has more sales than the high quality firm in a duopoly over which he can spread his fixed costs. As

mentioned earlier, there is no monopoly distortion in this model. Having a monopoly distortion would tend to reduce the quality choice of the monopolist as he will produce less than the optimal output so that there will be fewer units to spread the costs of quality over. Also, note that having two firms rather than one also shifts surplus from the sellers to the buyers even if it does not affect total surplus for given qualities. If this is desirable, that is the weight on consumer surplus exceeds that on profits, then entry, even if the monopolist provides perfect quality, may be desirable.

\section{Allowing for Production Costs}

While we have assumed zero production costs for simplicity so far, our results do not depend on this assumption. We consider the most basic extension where the constant marginal costs of production rise linearly with quality. That is, $c_{i}=m q_{i}$ where $m q_{i}$ is the constant marginal cost of a unit of quality $q_{i}$ and we assume $V>m$. The consumer's decision is unaffected by the introduction of production costs. However, where Firm $i$ once earned $P_{i}$ from every consumer who visited, it now earns $P_{i}-m q_{i}$. The equilibrium profits of the highest quality firm are equal to its profits when it chooses a 
price quality ratio of $V$, so that,

$$
\pi_{n}^{E} \stackrel{n-1}{=} \prod_{i=1}\left(1-q_{i}\right)(V-m) q_{n} .
$$

For these to equal its profits at $R_{0}$,

$$
\left(R_{0}-m\right)=\prod_{i=1}^{n-1}\left(1-q_{i}\right)(V-m) .
$$

In turn, this gives the profits of the other firms to be their profits at $R_{0}$ when they are visited first or,

$$
\pi_{i}^{E}=\left(R_{0}-m\right) q_{i}=\prod_{i=1}^{n-1}\left(1-q_{i}\right)(V-m) q_{i}
$$

for $i=1, . . n-1$.

It is easy to verify that appropriately replacing $\frac{P}{q}$ with $\left(\frac{P}{q}-m\right)$ and $V$ by $(V-m)$ in the equilibrium distribution functions derived earlier yields the equilibrium strategies in the presence of production costs. For example, with two firms, the equilibrium distribution is given by

$$
\begin{aligned}
& F_{L}\left(\frac{P}{q}\right)=\frac{1}{q_{L}}-\frac{\left(1-q_{L}\right)(V-m)}{q_{L}}\left(\frac{P}{q}-m\right)^{-1} \text { for } \frac{P}{q} \in\left[\frac{P_{H}^{*}}{q_{H}}, V\right] \\
& F_{H}\left(\frac{P}{q}\right)=\left\{\begin{array}{cc}
\frac{1}{q_{H}}-\frac{\left(1-q_{L}\right)(V-m)}{q_{H}}\left(\frac{P}{q}-m\right)^{-1} & \text { for } \frac{P}{q} \in\left[\frac{P_{H}^{*}}{q_{H}}, V\right) \\
1 & \text { for } \frac{P}{q}=V .
\end{array}\right.
\end{aligned}
$$

where $\left(\frac{P_{H}^{*}}{q_{H}}-m\right)=\left(1-q_{L}\right)(V-m)$.

Applying the same profit maximization procedure used above we can analyze the effects on quality choices. The addition of marginal cost of production reduces the marginal benefit of quality. Accounting for non zero marginal costs causes low quality firms to reduce their optimal quality choices. The resulting changes in the high quality firm's choices of quality depends critically on the nature of the cost of quality function. With concave cost of quality, the high quality producer continues to choose perfect quality regardless of marginal cost of production as long as $\prod_{i=1}^{n-1}\left(1-q_{i}\right)(V-m)>C(1)$. With convex cost of quality, the high quality producer joins the remaining firms in reducing its quality choice. 


\section{Conclusion}

In this paper we develop a new model of quality where quality is interpreted as the probability of being satisfied. We abstract from notions of asymmetric information, product defects, and brand loyalty. This leads to interesting theoretical results which explain common beliefs regarding quality competition, prices and profits and their relation to quality, as well as market structure and its relation to the nature of fixed costs. It helps explain a number of facts in the real world that are hard to explain using other models of quality.

The model presented above has a number of interesting features. First, we find that high quality firms make greater profits in equilibrium than do low quality firms. This confirms some of the ideas in the extensive Management Science literature on the importance of quality as a strategic variable and its link with profitability. Second, our equilibrium requires mixed strategies in price. We interpret these as a policy of sales. In this context, our model suggests that lower quality products go on sale more often than higher quality

ones. Also, while one might sometimes find a high quality product for a low price, one will not find a low quality good at a high price! Third, our model suggests that under certain conditions, convex costs of quality result in an infinite number of firms entering and all firms profits going to zero. However, if costs are concave, a finite number of firms enter, resulting in a natural oligopoly where the highest quality firm makes positive profits. Finally, although all firms are ex ante identical, as are all consumers, there is ex post variability in quality and price among firms. The model also has a number of interesting extensions and applications which we are pursuing. 


\section{Appendix 1}

Lemma $1 \frac{\partial \Pi_{H}\left(q, \underline{q}_{L}\right)}{\partial q}>\frac{\partial \Pi_{L}(q)}{\partial q}=0$ at $q=\underline{q}_{L}$.

This can be verified by noting that the slope of $\Pi_{H}\left(q, \underline{q}_{L}\right)$ evaluated at $q$ $=\underline{q}$ is given by:

$$
\left(1-\underline{q}_{L}\right) V-C^{\prime}\left(\underline{q}_{L}\right) .
$$

Comparing the slopes of $\Pi_{H}\left(q, \underline{q}_{L}\right)$ and $\Pi_{L}(q)$ at $q=\underline{q}_{L}$, that is comparing (21) with (2), reveals that the slope of the former exceeds that of the latter (which equals zero) as depicted in Figure 4.

Lemma $2 \underline{q}_{L}<\tilde{q}<1$.

Recall that $\Pi_{H}\left(\underline{q}_{L}, \underline{q}_{L}\right)=\Pi_{L}\left(\underline{q}_{L}\right)$. Because $\Pi_{H}\left(q_{H}, q_{L}\right)$ is increasing in $q_{H}$, we know $\Pi_{H}\left(1, \underline{q}_{L}\right)>\Pi_{L}\left(\underline{q}_{L}\right)$. Since $\Pi_{H}\left(q_{H}, q_{L}\right)$ is decreasing in $q_{L}, q_{L}$ must rise from $\underline{q}_{L}$ to $\tilde{q}$ for $\Pi_{H}(1, \tilde{q})=\Pi_{L}\left(\underline{q}_{L}\right)$. Hence, $\tilde{q}>\underline{q}_{L}$. This is depicted in Figure 4 . The value of $\Pi_{H}\left(q_{H}, q_{L}\right)$ at $q_{L}=1$ is negative. As, $\Pi_{L}\left(\underline{q}_{L}\right)$ is positive it follows by continuity arguments that $\tilde{q}<1$.

Lemma $3 \underline{q}_{L}<\tilde{q}<q_{L}^{c} \leq 1$ where $\tilde{q}$ and $q_{L}^{c}$ are defined in (5) and (6) respectively,

Again recall that $\Pi_{H}\left(q_{H}, \underline{q}_{L}\right)$ is concave and increasing in $q_{H}$ as well as being equal to $\Pi_{L}\left(\underline{q}_{L}\right)$ when $q_{H}=\underline{q}_{L}$ and increasing in $q_{H}$ at this point. Thus, $\Pi_{H}\left(q_{H}\left(\underline{q}_{L}\right), \underline{q}_{L}\right)>\Pi_{L}\left(\underline{q}_{L}\right)$ and $q_{H}\left(\underline{q}_{L}\right)>\underline{q}_{L}$. From this, the definition of $\tilde{q}$ and that $\Pi_{H}\left(q_{H}\left(q_{L}\right), q_{L}\right)$ decreases in $q_{L}$ and it follows that $\tilde{q}>\underline{q}_{L}$.

$q_{L}^{c}$ is uniquely defined and greater than $\underline{q}_{L}$ as $q_{H}\left(q_{L}\right)$ is downward sloping and lies above the 45 degree line at $q_{L}=\underline{q}_{L}$.

$>$ From the definition of $\Pi_{H}\left(q_{H}\left(q_{L}\right), q_{L}\right)$ and the fact that the switchover in profits occurs along the 45 degree line, its value at $q_{L}=q_{L}^{c}$ is given by:

$$
\begin{aligned}
\Pi_{H}\left(q_{H}\left(q_{L}^{c}\right), q_{L}^{c}\right) & =\Pi_{H}\left(q_{L}^{c}, q_{L}^{c}\right) \\
& =\Pi_{L}\left(q_{L}^{c}\right) \\
& <\Pi_{L}\left(\underline{q}_{L}\right) \\
& =\Pi_{H}\left(q_{H}(\tilde{q}), \tilde{q}\right) .
\end{aligned}
$$

Since $\Pi_{H}\left(q_{H}\left(q_{L}\right), q_{L}\right)$ falls as $q_{L}$ rises, it follows that $\tilde{q}<q_{L}^{c}$ which completes the proof. 


\section{Appendix 2}

Lemma $4 E\left(\pi_{i}\left(\left(\frac{P_{i}}{q_{i}}\right), F_{n-i}().\right)\right)=P_{i} \prod_{j \neq i}^{n}\left[1-F_{j}\left(\frac{P_{i}}{q_{i}}\right) q_{j}\right]$ denotes Firm $i^{\prime} s$ expected profits when it chooses $\frac{P_{i}}{q_{i}}$ and competes with $n-1$ other firms. $F_{n-i}($.$) denotes the vector of distribution functions used by all n$ firms but Firm $i$.

The proof is by induction. Let

$$
E\left(\pi_{i}\left(\left(\frac{P_{i}}{q_{i}}\right), F_{n-1-i}(.)\right)\right)=P_{i} \prod_{j \neq i}^{n-1}\left[1-F_{j}\left(\frac{P_{i}}{q_{i}}\right) q_{j}\right]
$$

be the expected profit of Firm $i$ when it chooses $\frac{P_{i}}{q_{i}}$ and competes with $n-$ 2 other firms that use mixed strategies $F_{n-1-i}($.$) . Suppose that Firm n$ enters the market using the mixed strategy $F_{n}\left(\frac{P_{i}}{q_{i}}\right)$. Firm $i$ with either be visited after Firm $n$ and earn expected profits, $\left(1-q_{n}\right) P_{i} \prod_{j \neq i}^{n-1}\left[1-F_{j}\left(\frac{P_{i}}{q_{i}}\right) q_{j}\right]$ or Firm $i$ will be visited before Firm $n$ and earn expected profits, $P_{i} \prod_{j \neq i}^{n-1}$ $\left[1-F_{j}\left(\frac{P_{i}}{q_{i}}\right) q_{j}\right]$. The former occurs with probability, $F_{n}\left(\frac{P_{i}}{q_{i}}\right)$ and the latter with probability, $\left[1-F_{n}\left(\frac{P_{i}}{q_{i}}\right)\right]$. Thus, Firm $i^{\prime} s$ new expected profits, denoted by $E\left(\pi_{i}\left(\left(\frac{P_{i}}{q_{i}}\right), F_{n-i}().\right)\right)$ are given by:

$$
\begin{aligned}
E\left(\pi_{i}(.)\right) & =\left[F_{n}\left(\frac{P_{i}}{q_{i}}\right)\left(1-q_{n}\right)+\left(1-F_{n}\left(\frac{P_{i}}{q_{i}}\right)\right)\right] P_{i} \prod_{j \neq i}^{n-1}\left[1-F_{j}\left(\frac{P_{i}}{q_{i}}\right) q_{j}\right] \\
& =P_{i} \prod_{j \neq i}^{n}\left[1-F_{j}\left(\frac{P_{i}}{q_{i}}\right) q_{j}\right] .
\end{aligned}
$$

Thus, the general form for expected profits in the mixed strategy equilibrium is given by $P_{i} \prod_{j \neq i}^{n}\left[1-F_{j}\left(\frac{P_{i}}{q_{i}}\right) q_{j}\right]=\pi_{i}^{E}$, where $\pi_{i}^{E}$ denotes the equilibrium level of profits for Firm $i$. The above equation holds for each firm which gives us $n$ equations.

Lemma $5 R_{i}<R_{i+1}$.

$$
R_{i}=\frac{\left(1-q_{i+1}\right)^{n-(i+1)}\left(1-q_{i}\right)}{\left(1-q_{i}\right)^{n-i}} \frac{\prod_{t=i+1}^{n-1}\left(1-q_{t}\right)}{\left(1-q_{i+1}\right)^{n-(i+1)}} V=\frac{\left(1-q_{i+1}\right)^{n-(i+1)}}{\left(1-q_{i}\right)^{n-(i+1)}} R_{i+1}<R_{i+1}
$$


Lemma $6 F_{j}\left(R_{0}\right)=0$ for all $j$.

$$
F_{j}\left(R_{0}\right)=\frac{1-\left[V\left[V \prod_{t=1}^{n-1}\left(1-q_{t}\right)\right]^{-1} \prod_{t=1}^{n-1}\left(1-q_{t}\right)\right]^{\frac{1}{n}}}{q_{j}}=\frac{1-1}{q_{j}}=0 .
$$

Lemma $7 \quad F_{i}($.$) , as defined above, is a continuous function except for F_{n}($. which jumps up at $V . F_{n}(V)=\frac{q_{n-1}}{q_{n}}$ so that $F_{n}($.$) has a mass point of 1-\frac{q_{n-1}}{q_{n}}$ at $V$.

The only candidates for mass points are points at which some firm drops out as it is here that their definition changes. First we check that there is no mass point in a firm's distribution function at the point where it drops out as long as it does not make the highest quality. At $R_{i}$ the distribution function of Firm $i$ coming from below is

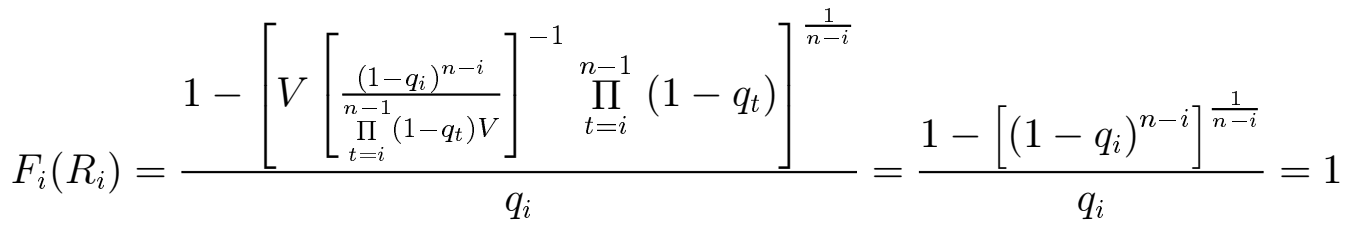

so that Firm $i$ drops out at $R_{i}$.

Note that $R_{i}$ is defined by $F_{i}\left(R_{i}\right)=1$. Thus, given that $R_{n-1}=V$, we can confirm that $F_{n-1}(V)=1$

$$
F_{n-1}(V)=\frac{1-\left[\prod_{t=n-1}^{n-1}\left(1-q_{t}\right) V[V]^{-1}\right]}{q_{n-1}}=\frac{1-\left(1-q_{n-1}\right)}{q_{n-1}}=1
$$

After the third highest quality firm has dropped out at $R_{n-2}$ the remaining two firms compete just as they do in the two firm case detailed above. Consistent with the above results, the highest quality firm has a mass point of $1-\frac{q_{n-1}}{q_{n}}$ at the maximum price quality ratio, $V$. This is seen by considering the limit of the distribution as $x$ approaches $V$ from below. By (8).

$$
\lim _{\frac{p}{q} \rightarrow V} F_{n}\left(\frac{p}{q}\right)=\frac{1-\left[V[V]^{-1} \prod_{t=n-1}^{n-1}\left(1-q_{t}\right)\right]}{q_{n}}=\frac{q_{n-1}}{q_{n}} .
$$


Next we show that there are no mass points where other firms drop out so that $F($.$) is continuous. This is done by considering the limits of F_{n-j}\left(\frac{p}{q}\right)$ as $\frac{p}{q}$ approaches $R_{n-i}$ from below and from above

$$
\begin{gathered}
\lim _{\frac{p}{q} \rightarrow R_{n-i}} F_{n-j}\left(\frac{p}{q}\right)=\lim _{R_{n-i} \leftarrow \frac{p}{q}} F_{n-j}\left(\frac{p}{q}\right) . \\
\lim _{\frac{p}{q} \rightarrow R_{n-i}} F_{n-j}\left(\frac{p}{q}\right)=\frac{1-\left[V[x]^{-1} \prod_{t=n-i}^{n-1}\left(1-q_{t}\right]^{\frac{1}{i}}\right.}{q_{n-j}^{n-1}} \\
\lim _{R_{n-i} \leftarrow \frac{p}{q}} F_{n-j}\left(\frac{p}{q}\right)=\frac{1-\left[V[x]^{-1} \prod_{t=n-i+1}^{n-1}\left(1-q_{t}\right)\right]^{\frac{1}{i-1}}}{q_{n-j}} .
\end{gathered}
$$

Our proof will be complete if we can show that

$$
\left[V\left[R_{n-i}\right]^{-1} \prod_{t=n-i}^{n-1}\left(1-q_{t}\right)\right]^{\frac{1}{i}}=\left[V\left[R_{n-i}\right]^{-1} \prod_{t=n-i+1}^{n-1}\left(1-q_{t}\right)\right]^{\frac{1}{i-1}} .
$$

Dividing both sides by $\left[V\left[R_{n-i}\right]^{-1} \underset{t=n-i+1}{\prod_{t-1}^{n-1}}\left(1-q_{t}\right)\right]^{\frac{1}{i}}$ yields,

$$
\begin{aligned}
\left(1-q_{n-i}\right)^{\frac{1}{i}} & =\left[V\left[R_{n-i}\right]^{-1} \prod_{t=n-i+1}^{n-1}\left(1-q_{t}\right)\right]^{\frac{1}{(i-1) i}} \\
& =\left[V\left[\frac{\left(1-q_{n-i}\right)^{i}}{V \prod_{t=n-i}^{n-1}\left(1-q_{t}\right)}\right] \prod_{t=n-i+1}^{n-1}\left(1-q_{t}\right)\right]^{\frac{1}{(i-1) i}} \\
& =\left[\left(1-q_{n-i}\right)^{i-1}\right]^{\frac{1}{(i-1) i}} \\
& =\left(1-q_{n-i}\right)^{\frac{1}{i}} .
\end{aligned}
$$

Proposition 7 In a mixed strategy equilibrium with $n$ firms, each producing a quality $q_{i}$, where $0=q_{0} \leq q_{1} \leq q_{2} \leq . . \leq q_{n}$, each firm makes profits of $\pi_{i}^{E}$ and mixes according to the distribution function $F_{i}\left(\frac{p}{q}\right)$ where:

$$
\pi_{i}^{E}=V q_{i} \prod_{t=1}^{n-1}\left(1-q_{t}\right)
$$


and

$$
F_{j}\left(\frac{P}{q}\right)=\frac{1-\left[V\left[\frac{P}{q}\right]^{-1} \prod_{t=i}^{n-1}\left(1-q_{t}\right)\right]^{\frac{1}{n-i}}}{q_{j}}
$$

for $\frac{P}{q} \in\left[R_{i-1}, R_{i}\right)$ and $i \leq j$. For $i>j$,

$$
F_{j}\left(\frac{P}{q}\right)=1
$$

This defines the distribution function for Firm $j$ over its support.

The proof consists of checking that Firm $j$ obtains $\pi_{j}^{E}$ as profits in the support of its distribution and that profits elsewhere are no higher than $\pi_{j}^{E}$. Evaluating the expected profits of Firm $j$ in the range $\left(R_{k-1}, R_{k}\right]$ for $k-1<j$ gives the profits of Firm $j$ for $R \in\left(R_{k-1}, R_{k}\right)$ to be

$$
E\left(\pi_{j}\left(\frac{P_{j}}{q_{j}}\right)\right)=P_{j}\left[\prod_{s=1}^{k-1}\left(1-q_{s}\right)\right]\left[\prod_{t=k, t \neq j}^{n}\left[1-F_{t}\left(\frac{P_{j}}{q_{j}}\right) q_{t}\right]\right] .
$$

In the region $\left(R_{k-1}, R_{k}\right)$,

$$
\left[1-F_{t}\left(\frac{P_{j}}{q_{j}}\right) q_{t}\right]=\left[\left(\frac{P_{j}}{q_{j}}\right)^{-1} V \prod_{r=k}^{n-1}\left(1-q_{r}\right)\right]^{\frac{1}{n-k}}
$$

by the definition of $F_{t}($.$) . Note that this is independent of t$, so that in equilibrium,

$$
\begin{aligned}
E\left(\pi_{j}\left(\frac{P_{j}}{q_{j}}\right)\right) & =P_{j}\left[\prod_{s=1}^{k-1}\left(1-q_{s}\right)\right]\left[\prod_{\substack{t=k \\
t \neq j}}^{n}\left[\left(\frac{P_{j}}{q_{j}}\right)^{-1} V \prod_{r=k}^{n-1}\left(1-q_{r}\right)\right]^{\frac{1}{n-k}}\right] \\
& =P_{j}\left[\prod_{s=1}^{k-1}\left(1-q_{s}\right)\right]\left(\frac{P_{j}}{q_{j}}\right)^{-1} V \prod_{r=k}^{n-1}\left(1-q_{r}\right) \\
& =\left[\prod_{s=1}^{n-1}\left(1-q_{s}\right)\right] q_{j} V=\pi_{j}^{E} .
\end{aligned}
$$

All firms have a common lower bound for the support of their mixed strategies of $R_{0}$.

Consider the returns to choosing a ratio outside the support $\left(R_{0}, V\right]$. As before choosing above $V$ yields zero profits because the price exceeds the 
expected value to the consumer. Choosing a ratio below $R_{0}$ would yield Firm $i$ a certain profit slightly less than $q_{i} R_{0}$. This will not be chosen because the mixed strategy yields $q_{i} R_{0}$ for Firm $i$

What about choosing a price above its drop out point? The expected profits of Firm $j$ in the range $\left(R_{k-1}, R_{k}\right]$ for $k-1 \geq j$ correspond to the profits in the region where Firm $j$ has already dropped out. In this region only firms with an index greater than or equal to $k$ remain active. Thus profits for Firm $j$ are given by

$$
\begin{aligned}
E\left(\pi_{j}\left(\frac{P_{j}}{q_{j}}\right)\right) & =P_{j}\left[\prod_{\substack{s=1 \\
s \neq j}}^{k-1}\left(1-q_{s}\right)\right]\left[\prod_{t=k}^{n}\left[1-F_{t}\left(\frac{P_{j}}{q_{j}}\right) q_{t}\right]\right] \\
& \left.=P_{j}\left[\prod_{\substack{s=1 \\
s \neq j}}^{k-1}\left(1-q_{s}\right)\right]\left[\left(\frac{P_{j}}{q_{j}}\right)^{-1} V \prod_{r=k}^{n-1}\left(1-q_{r}\right)\right]^{\frac{n-k+1}{n-k}}\right] \\
& =\left[\prod_{r=1}^{n-1}\left(1-q_{r}\right)\right] V\left\{\left[\left(\frac{P_{j}}{q_{j}}\right)^{-1} V \prod_{r=k}^{n-1}\left(1-q_{r}\right)\right]^{\frac{1}{n-k}} q_{j}\left(1-q_{j}\right)^{-1}\right\} \\
& =R_{0}\left[1-F_{t}\left(\frac{P_{j}}{q_{j}}\right) q_{t}\right] q_{j}\left(1-q_{j}\right)^{-1}
\end{aligned}
$$

for all $t$ corresponding to firms which are active in this region. This function is decreasing in $R$ so that if we can show that it is less than the profits of Firm $j$ in equilibrium for $R=R_{k-1}$ we are done. At $R_{k-1}$

$$
\begin{aligned}
E\left(\pi_{j}\left(R_{k-1}\right)\right) & =R_{0}\left[1-F_{k-1}\left(R_{k-1}\right) q_{k-1}\right] q_{j}\left(1-q_{j}\right)^{-1} \\
& =R_{0} q_{j}\left[1-q_{k-1}\right] q_{j}\left(1-q_{j}\right)^{-1} \\
& =\pi_{j}^{E} \frac{\left(1-q_{k-1}\right)}{\left(1-q_{j}\right)} \leq \pi_{j}^{E}
\end{aligned}
$$

as $\frac{\left(1-q_{k-1}\right)}{\left(1-q_{j}\right)} \leq 1$ since $j<k$. 


\section{Appendix 3}

In this section we explore the effect of free entry using a simple example where $C(q)=q^{2}, V=1$ and $n=3$. First, consider the almost symmetric equilibrium. The choice of quality by the two low quality firms when there are three firms in total, $q^{*}(3)$, is implicitly defined by (16). Hence

$$
\left(1-q^{*}\right)^{(n-2)}=\left(1-q^{*}\right)=\frac{2 q^{*}}{1-2 q^{*}} .
$$

This gives $q^{*}(3)=.21922$. The quality choice for the high quality firm is given by $(17)$ so that $q_{n}^{*}(3)$ is defined by,

$$
\left(1-q^{*}\right)^{n-1}=\left(1-q^{*}\right)^{2}=2 q_{n}^{*} .
$$

This equation is satisfied when $q_{n}^{*}(3)=.30481$.

If we look at the free entry case, we need to ensure that no firm wishes to enter. Given that the high quality firm makes more profits than the low quality ones, this position will always be chosen. This means that the low quality firms must make zero profits when $n$ satisfies (18). Hence,

$$
q^{*}(n)\left(1-q^{*}(n)\right)^{(n-1)}-\left(q^{*}(n)\right)^{2}=0 .
$$

Substituting $\left(1-q^{*}\right)^{n-1}$ from (22) into (24) gives,

$$
\left(1-q^{*}(n)\right) \frac{2 q^{*}(n)}{1-2 q^{*}(n)}=q^{*}(n) .
$$

Simplifying gives,

$$
2 q^{*}(n)=q^{*}(n)
$$

so that the only solution is $q^{*}(n)=0$. This is the expected result since Section 7 show that under free entry $n$ goes to infinity and $q^{*}(n)$, the quality chosen by all but the highest quality firm, goes to zero. Of course, from (23) it follows that the quality choice of the high quality firm will also converge to zero as $n$ goes to infinity.

Now consider the asymmetric equilibrium when there are three firms. Can such an equilibrium exist? The first order conditions for firms 1, 2 and 3 respectively are,

$$
\left(1-q_{2}\right)=\frac{2 q_{1}}{1-2 q_{1}}
$$




$$
\begin{gathered}
\left(1-q_{1}\right)=\frac{2 q_{2}}{1-2 q_{2}} \\
\left(1-q_{1}\right)\left(1-q_{2}\right)=2 q_{3} .
\end{gathered}
$$

Figure 11 helps depict the conditions for a solution. The curves $y=(1-q)$, and $y=\frac{2 q}{1-2 q}$ are depicted by the downward sloping line with unit slope starting at $y=1$, and the convex curve asymptotic to the vertical line at $q=1 / 2$. The almost symmetric solution where $q_{1}=q_{2}$ occurs at $q^{*}$ where these two intersect.

What about the asymmetric solution? Let us look at what values of $q_{1}$ and $q_{2}$ with $q_{1}<q_{2}$ can satisfy the above three equations. For $q_{1}<q_{2}$ to be a solution, the height of $y=(1-q)$ must equal that of $y=\frac{2 q}{1-2 q}$ with $y=(1-q)$ being to the right of $y=\frac{2 q}{1-2 q}$ since $q_{1}<q_{2}$. The quality choices $q_{1}^{\prime}$ and $q_{2}^{\prime}$ directly below points $A$ and $B$ for example satisfy (25). Can they also satisfy $(26)$ ? They can if $\frac{2 q_{2}^{\prime}}{1-2 q_{2}^{\prime}}=\left(1-q_{1}^{\prime}\right)$. However, it is obvious from Figure 11 that the points on $y=\frac{2 q}{1-2 q}$ and $y=(1-q)$ that lie directly above the quality choices $q_{1}^{\prime}$ and $q_{2}^{\prime}$ do not have the same height. In essence for these heights to be the same there must be four points, which lie on a perfect $X$, on the two curves. Moreover, for such a solution to exist as $n$ increases, such conditions must be satisfied for each $n$ ! 
Table 1

Return on Investment and Net Profit as a Percentage of Sales, by Strategic Position (PIMS Database)

\begin{tabular}{l|l|l|l|} 
& \multicolumn{3}{c}{ Quality Relative to Competitors } \\
& Low & Average & High \\
\hline Return on Investment & 13 & $17-21$ & 30 \\
\hline Net Profit as a Percentage of Sales & 6 & $8-9$ & 14 \\
\hline
\end{tabular}

Source: Robert D. Buzzell, "Product Quality", The PIMS letter on Business Strategy, No. 4, 1978.

Table 2

Return on Investment, by Strategic Position

\begin{tabular}{ll|l|l|l|} 
& \multicolumn{4}{c}{ Quality Relative to Competitors } \\
& & Low & Medium & High \\
\cline { 2 - 5 } Cost Relative & Low & 11.7 & 14.2 & 19.7 \\
\cline { 2 - 5 } to Competitors & Medium & 6.8 & 13.9 & 17.9 \\
\cline { 2 - 5 } & High & 3.4 & 4.8 & 13.8 \\
\cline { 2 - 5 } & & &
\end{tabular}

Source: J. Kay, Financial Times (10 May 1996) p. 17. 


\section{References}

[1] Bouckaert, Jan and Hans Degryse (1998) "Price Competition Between an Expert and a Non-Expert". Tilberg University, Center for Economic Research, Discussion Paper No. 9849.

[2] Buzzell, Robert D. (1978) "Product Quality", The PIMS letter on Business Strategy, No. 4.

[3] Buzzell, Robert D. and Fredrick D. Wiersema (1981) "Successful ShareBuilding Strategies". Harvard Business Review, January-February, pp. 135-144.

[4] d'Aspremont C., J. Jaskold Gabszewicz and J.F. Thisse (1979) "On Hotelling's 'Stability in Competition' ". Econometrica, Vol. 47, No. 5, pp. 1145-1150.

[5] Darlin, Damon (1985) "Although U.S. Cars are Improved, Imports Still Win Quality Survey" Wall Street Journal, December 16th, p. 29.

[6] Emons, Winand (1999) "Product Differentiation and Price Competition between a Safe and a Risky Seller", Mimeo, University of Bern. An earlier version is CEPR Working Paper No. 2041, December 1998.

[7] Kay, J. (1996) Financial Times, May 10th, p. 17.

[8] Krishna, Kala and Tor Winston. (1998). "A New Model of Quality", NBER Working Paper No. 6580.

[9] Main, Jeremy. "The Battle for Quality Begins", Fortune, December 29, 1980, p. 33.

[10] Mussa, M. and S. Rosen (1978). "Monopoly and Product Quality," Journal of Economic Theory, Vol. 18, No. 2, pp. 301-317.

[11] Peters, Thomas J. and Robert H. Waterson, Jr. (1982). "In Search of Excellence: Lessons from America's Best Run Companies". New York: Harper and Row.

[12] Porter, Michael E. (1980) "Competitive Strategies: Techniques for Analyzing Industries and Companies". New York: The Free Press, pp. 37-38. 
[13] Shaked, Avner and John Sutton. (1983). "Natural Oligopolies", Econometrica, Vol. 51, No. 5, pp. 1469-1484.

[14] Sheshinski, Eytan. (1976). "Price, Quality and Quantity Regulation in Monopoly Situations", Economica, Vol. 43, pp. 127-138.

[15] Shetty, Y.K. and Vernon M. Buehler (Ed.) (1983) "Quality and Productivity Improvements: U.S. and Foreign Company Experiences", Chicago: Manufacturing Productivity Center.

[16] Shetty, Y.K. and Vernon M. Buehler (Ed.) (1985) "Productivity and Quality Through People; Practices of Well Managed Companies" Westport Conn; Quorum Books.

[17] Shetty, Y.K. (1987). "Product Quality and Competitive Strategy", Business Horizons, May-June.

[18] Spence, A. Michael, (1976). "Monopoly, Quality and Regulation," Bell Journal of Economics, Autumn, pp. 417-429.

[19] Stiles, Edward M. (1977). Handbook for Total Quality Assurance, Englewood Cliffs, N.J.: Prentice Hall, p.3.

[20] Swan, Peter C. (1970). "Durability of Consumption Goods," American Economic Review, Vol. 60, No. 5, pp. 884-894.

[21] Tirole, Jean (1988). The Theory of Industrial Organization, Chapter 7.5, MIT Press, Cambridge, MA.

[22] Weitzman, Martin L. (1979). "Optimal search for the best alternative." Econometrica, Vol. 47, No. 3, pp.641-654. 


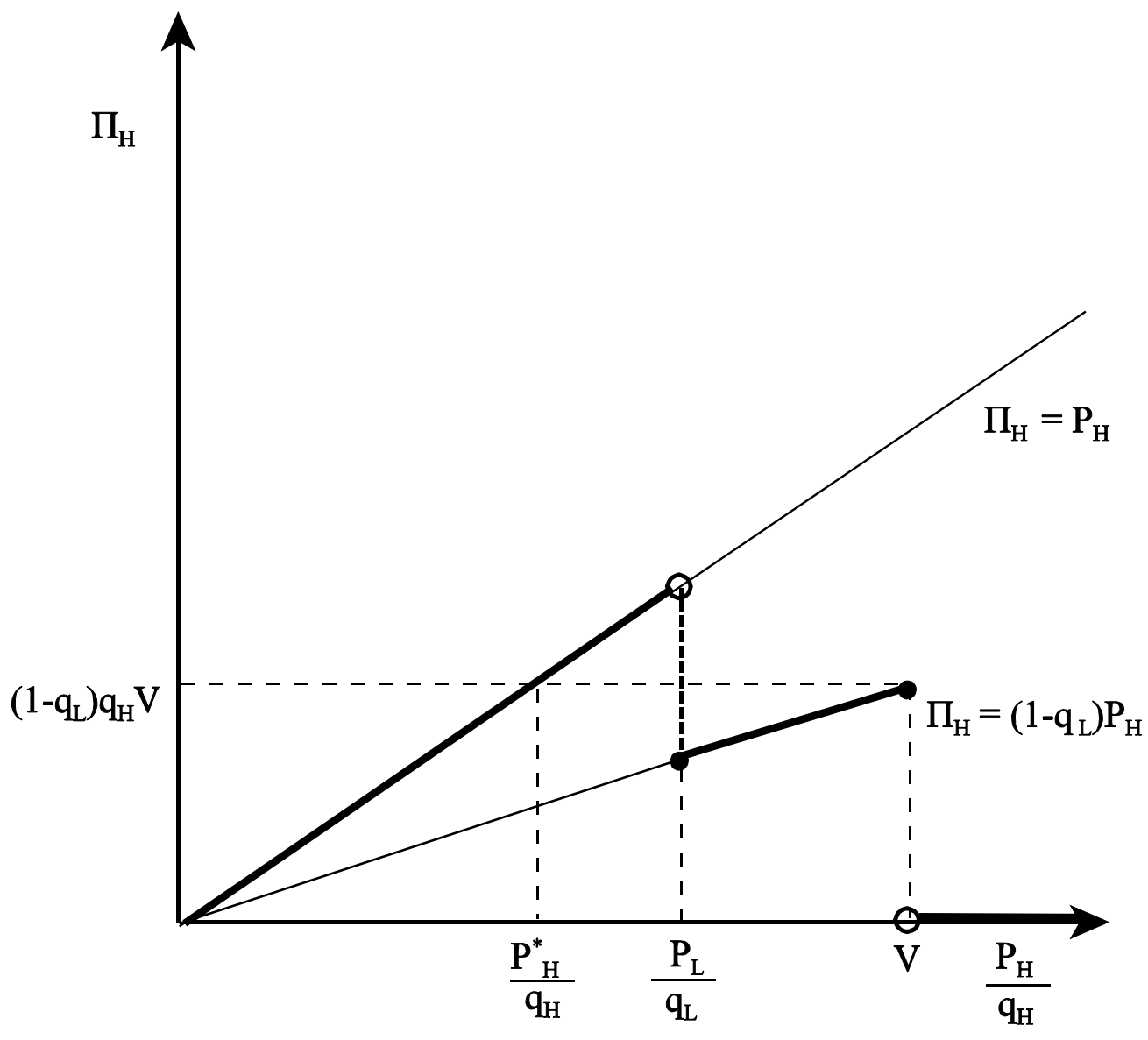

Profits of Firm $\mathrm{H}$

Figure 1 


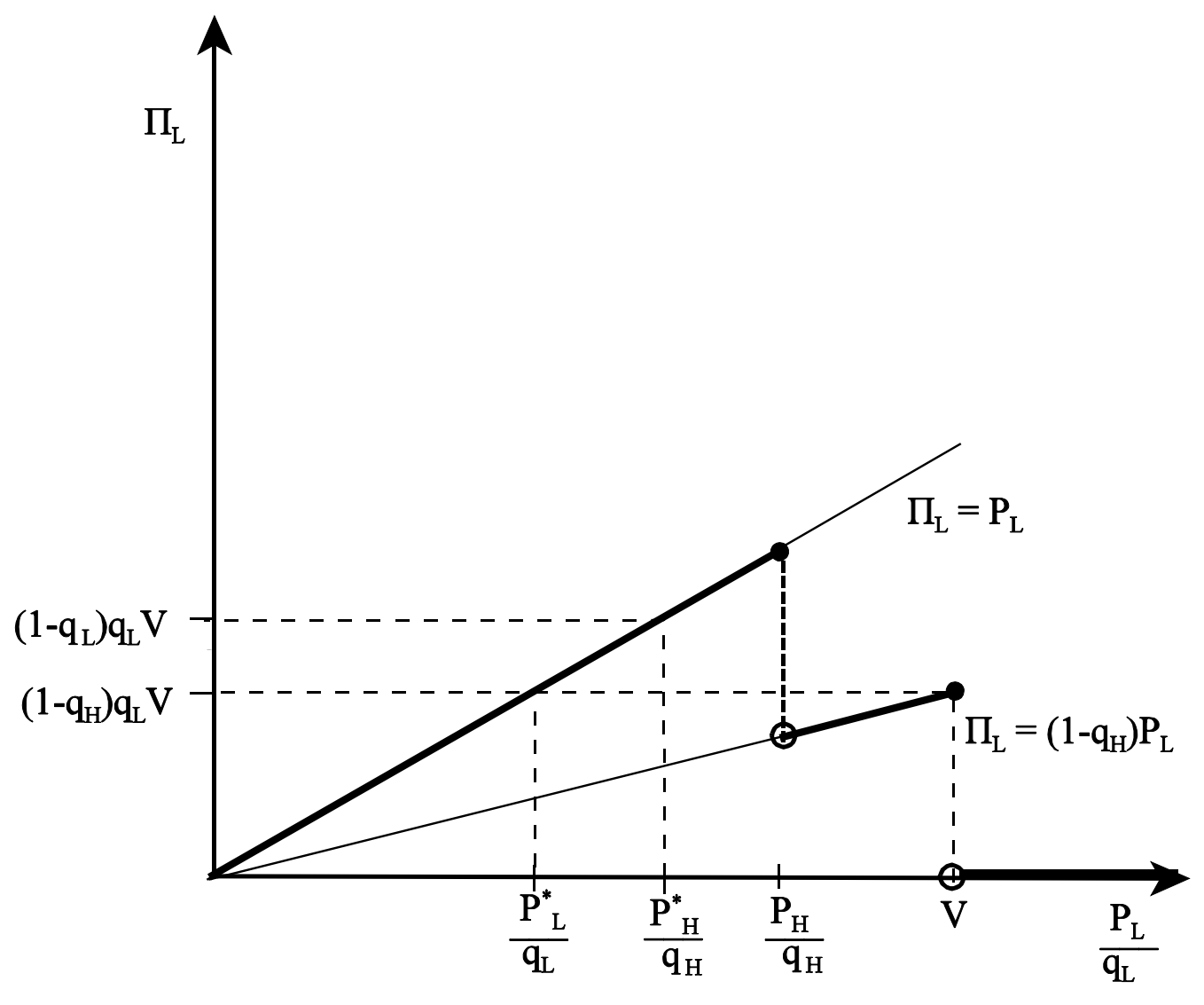

Profits of Firm L

Figure 2 


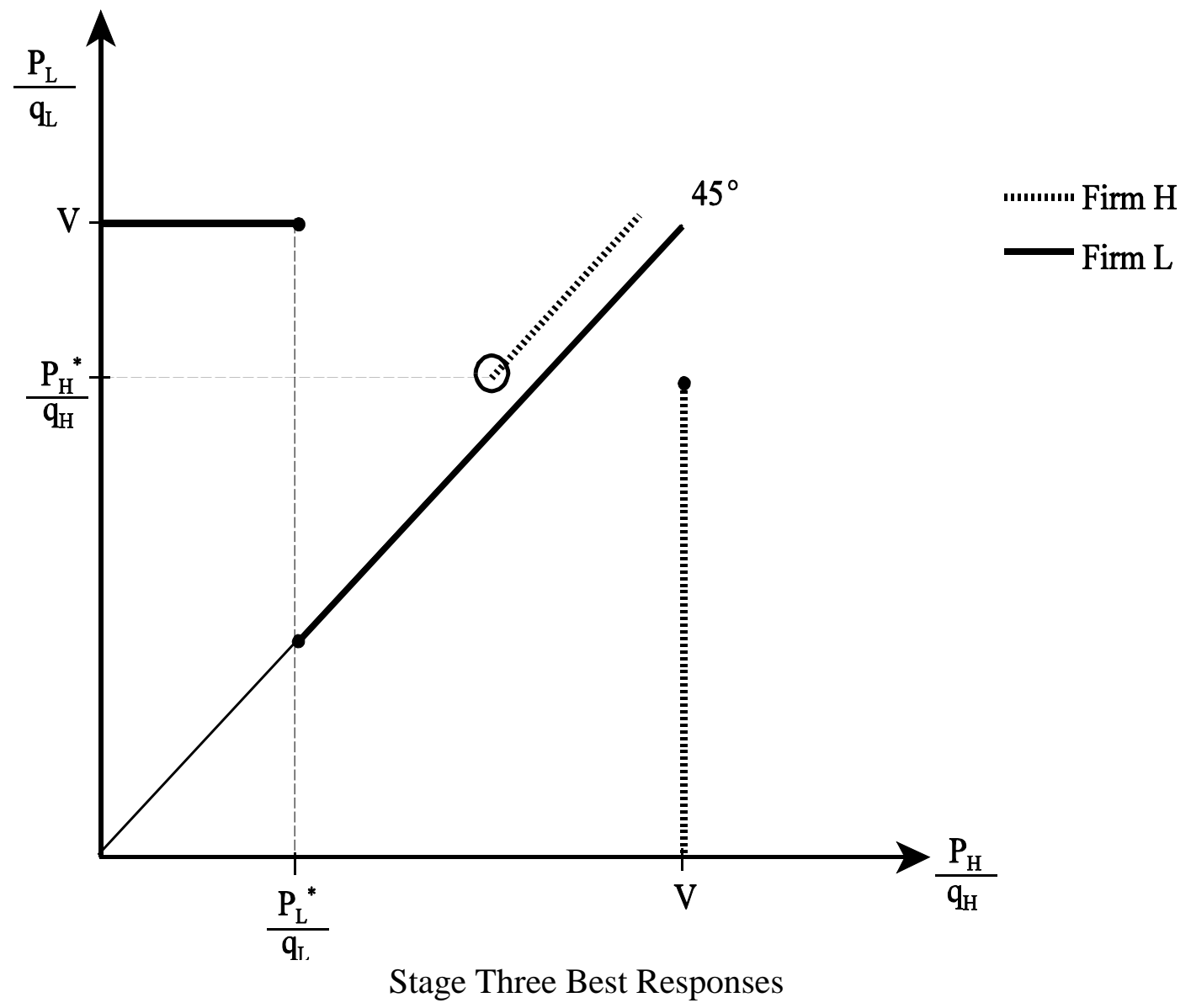

Figure 3 


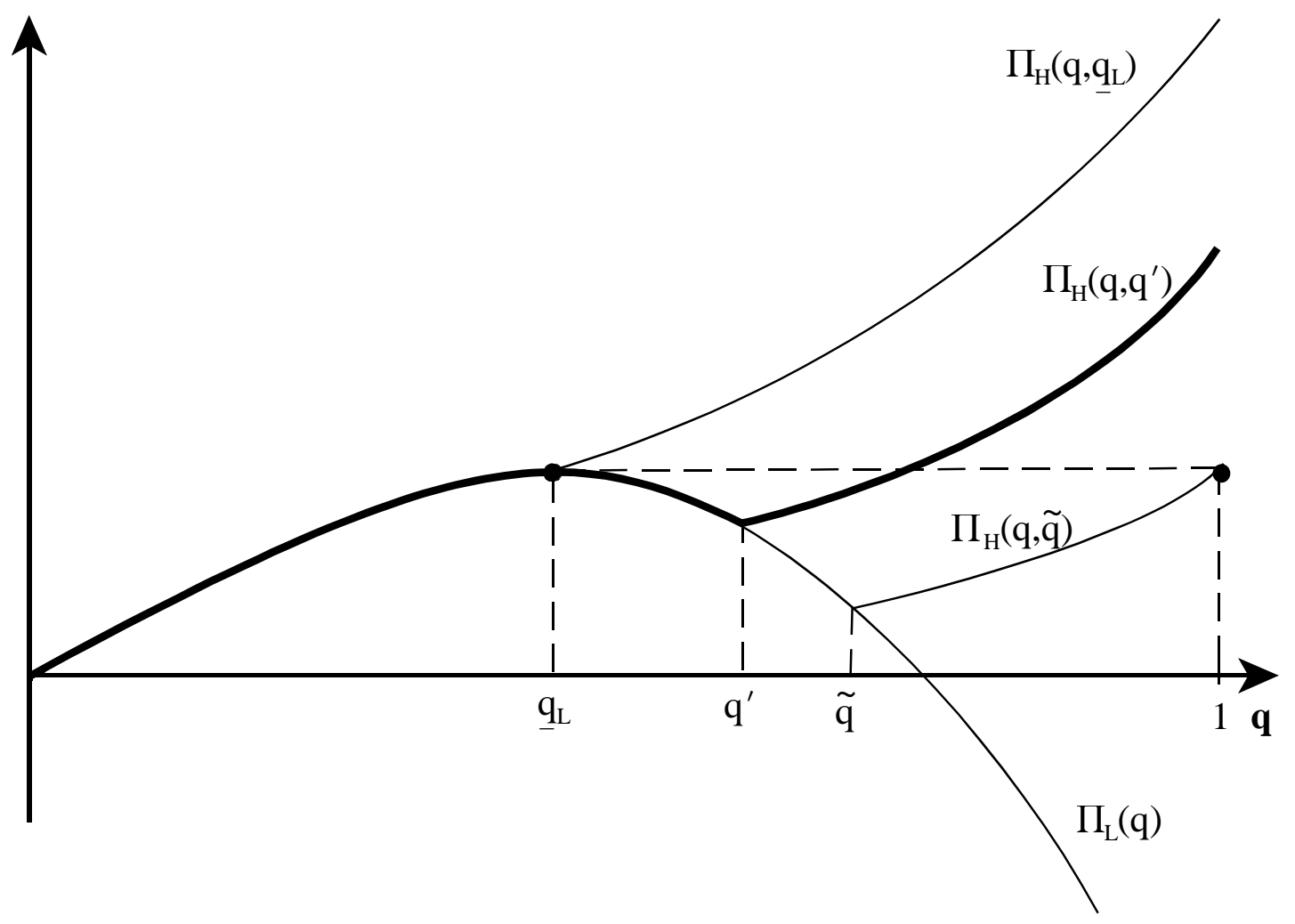

Profits with Concave Costs of Quality

Figure 4 


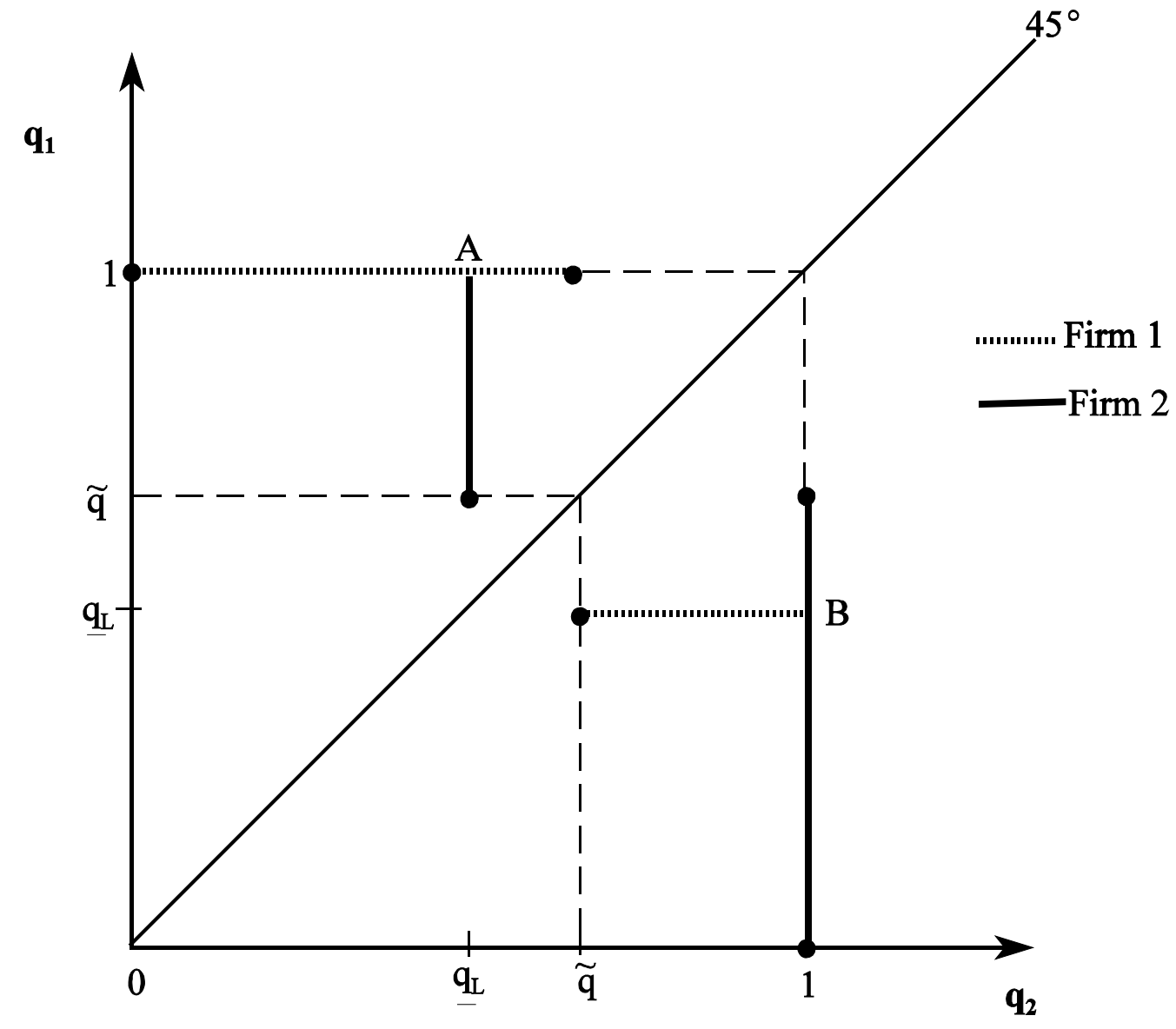

Quality Choices with Concave Costs of Quality

Figure 5 


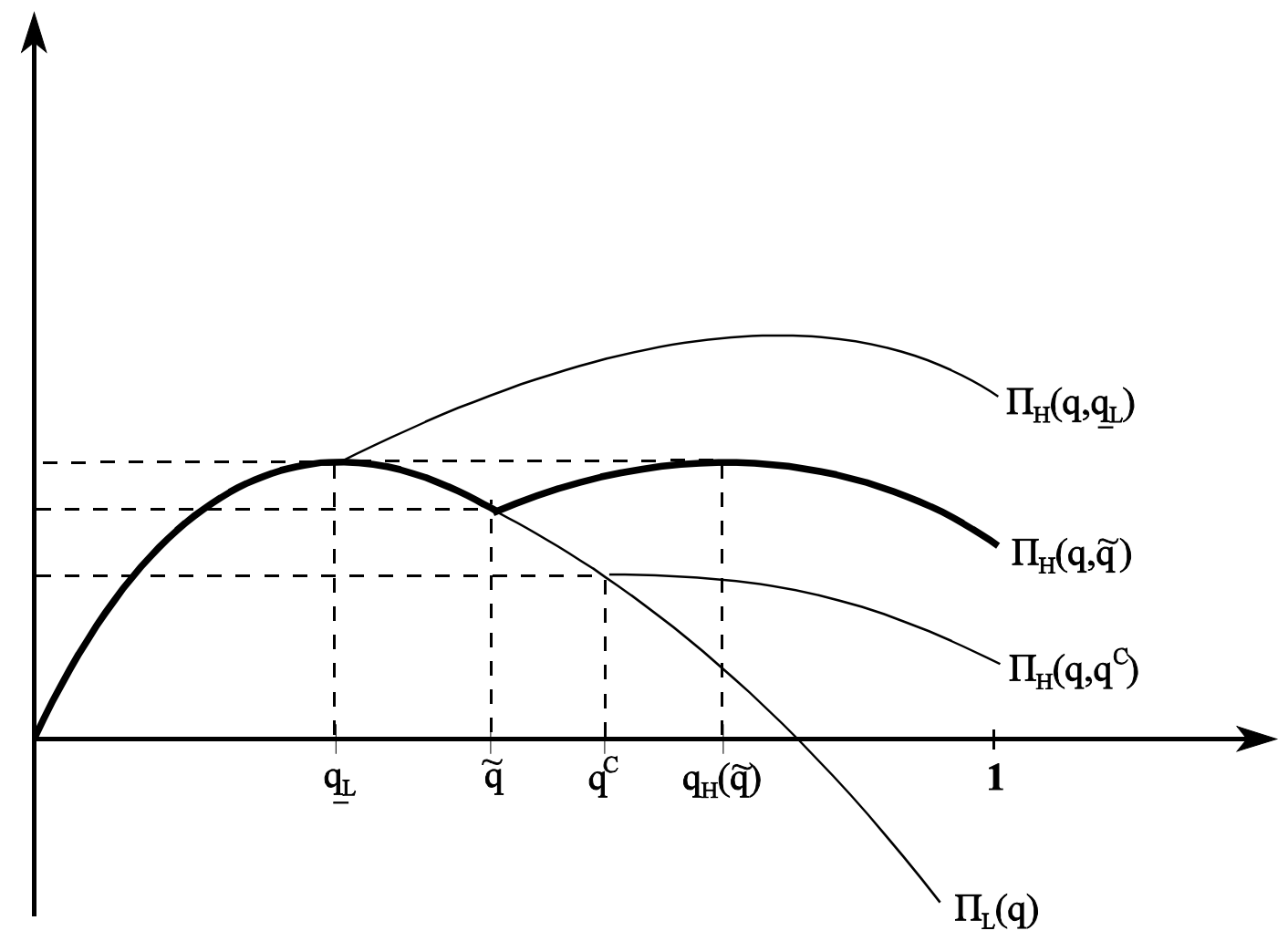

Profits with Convex Costs of Quality

Figure 6 


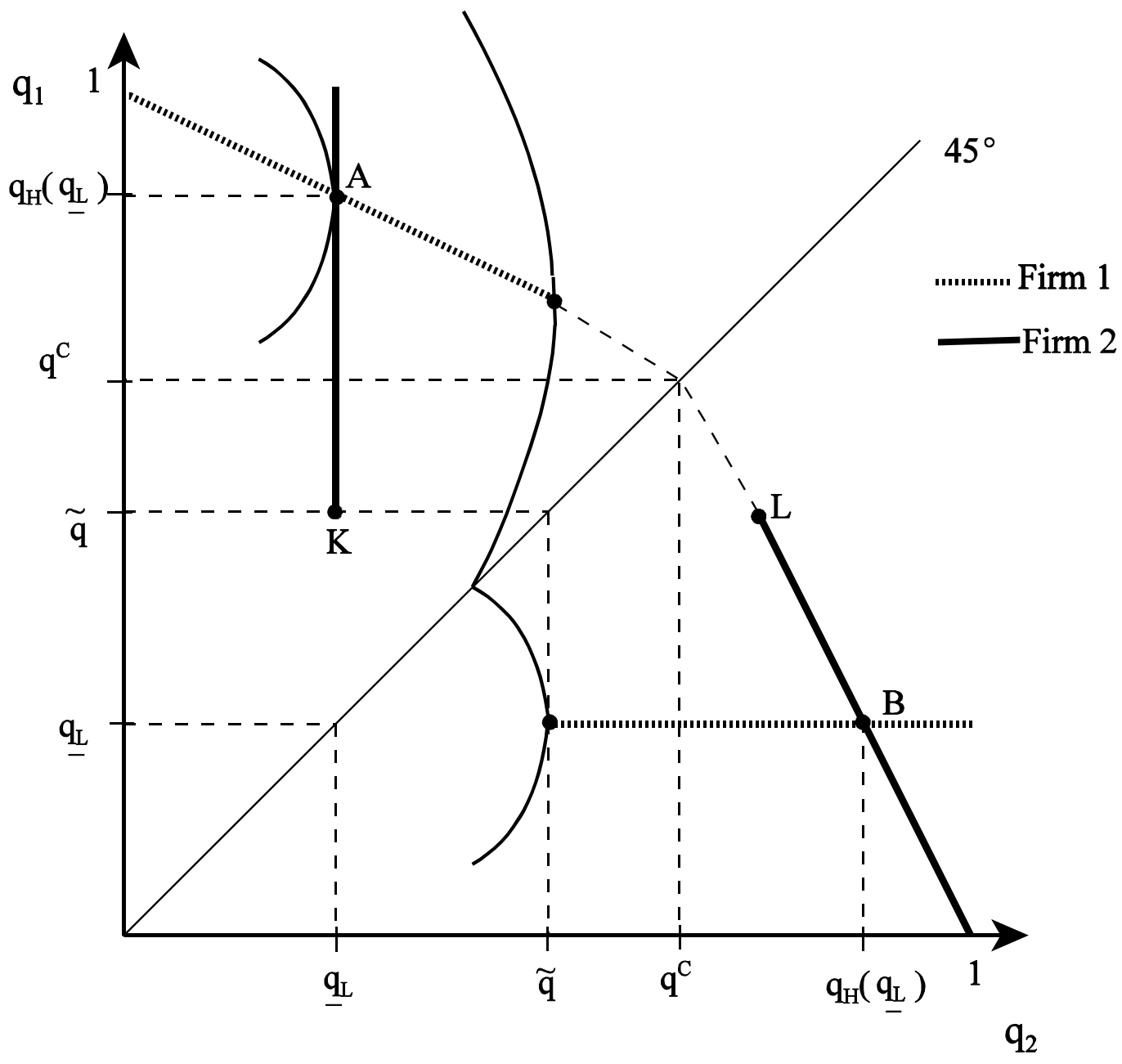

Quality Choices with Convex Costs of Quality

Figure 7 


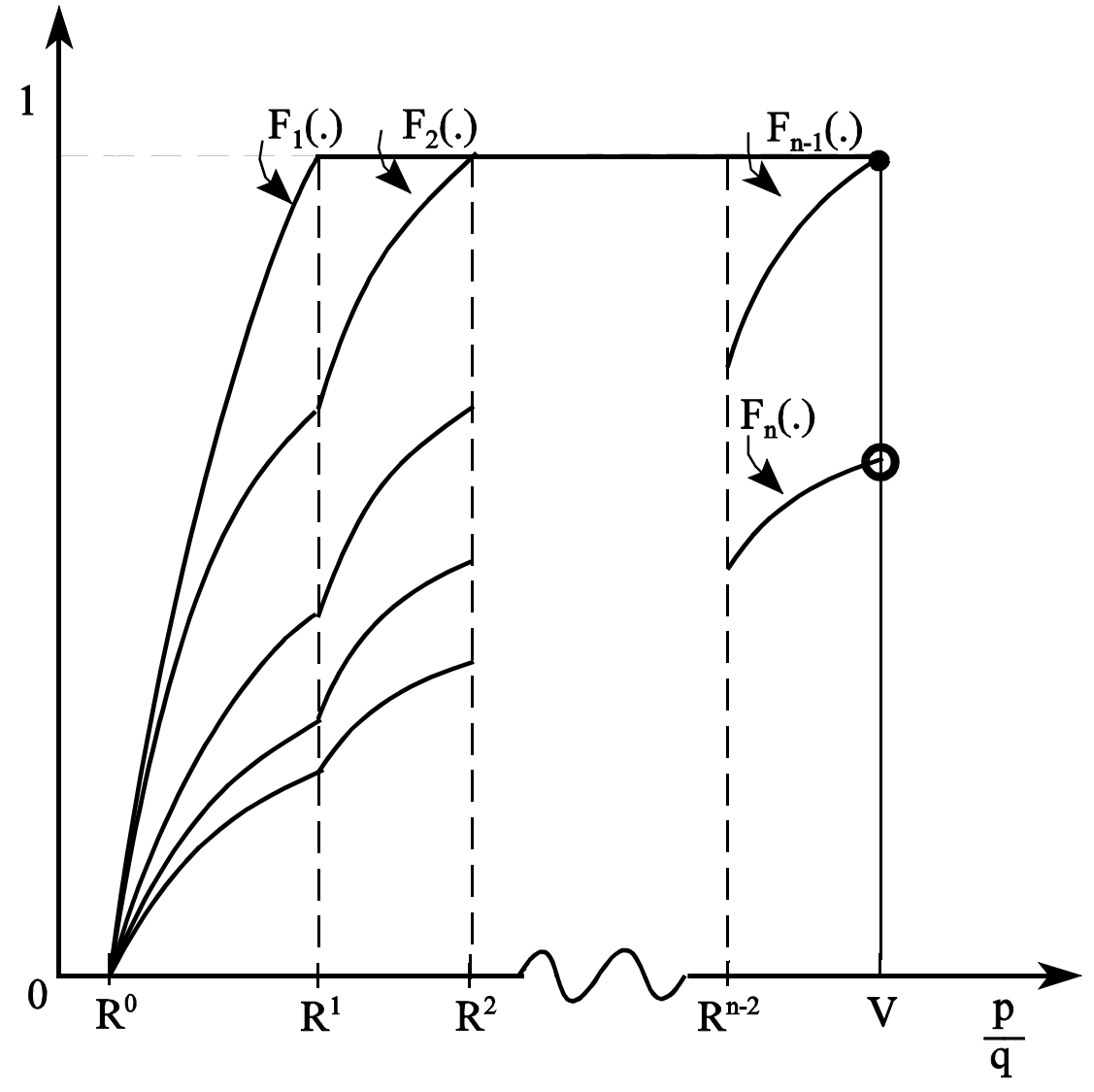

Cumulative Distribution Functions with n Firms Figure 8 


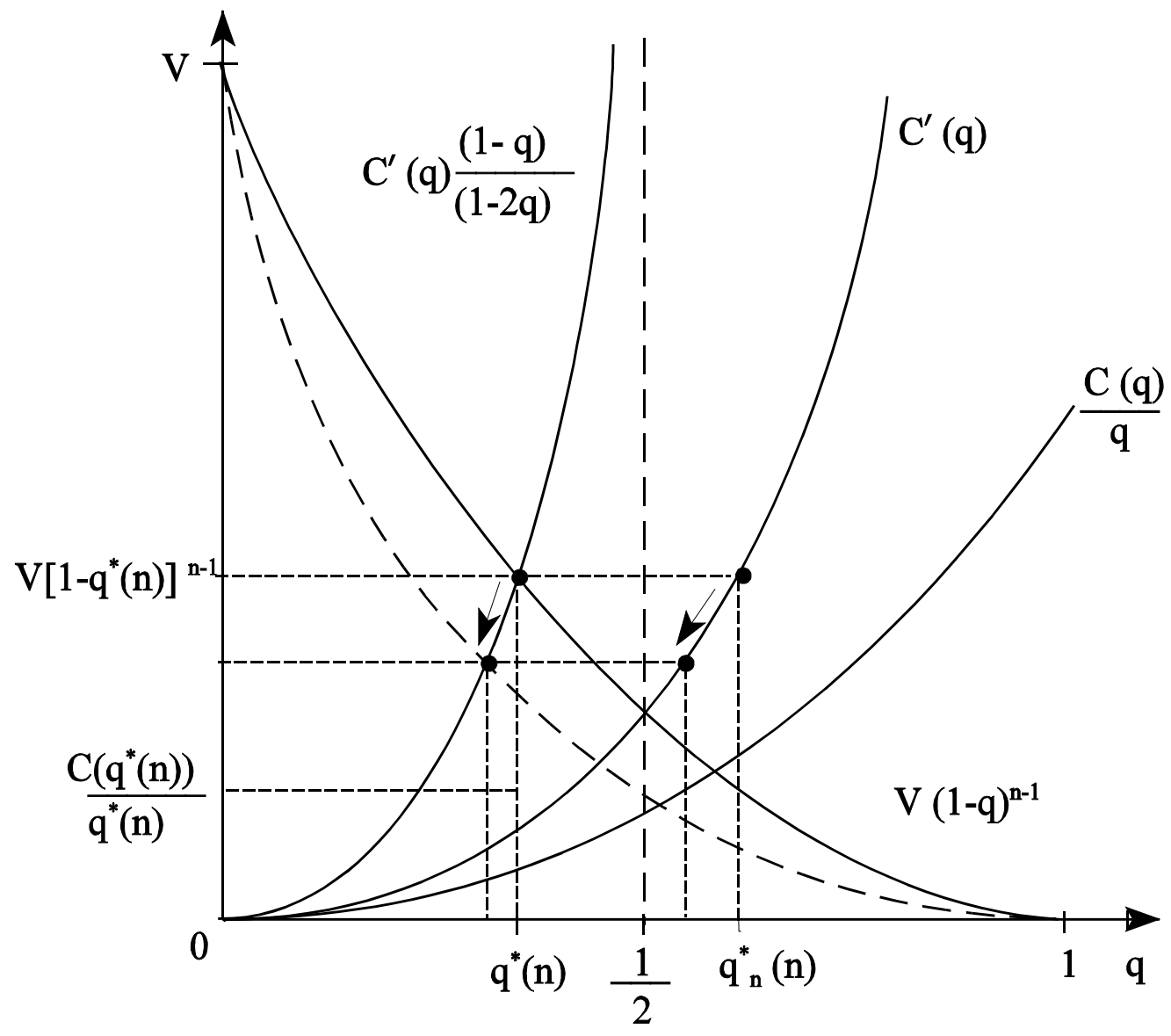

Almost Symmetric Equilibrium with Convex Costs

Figure 9 


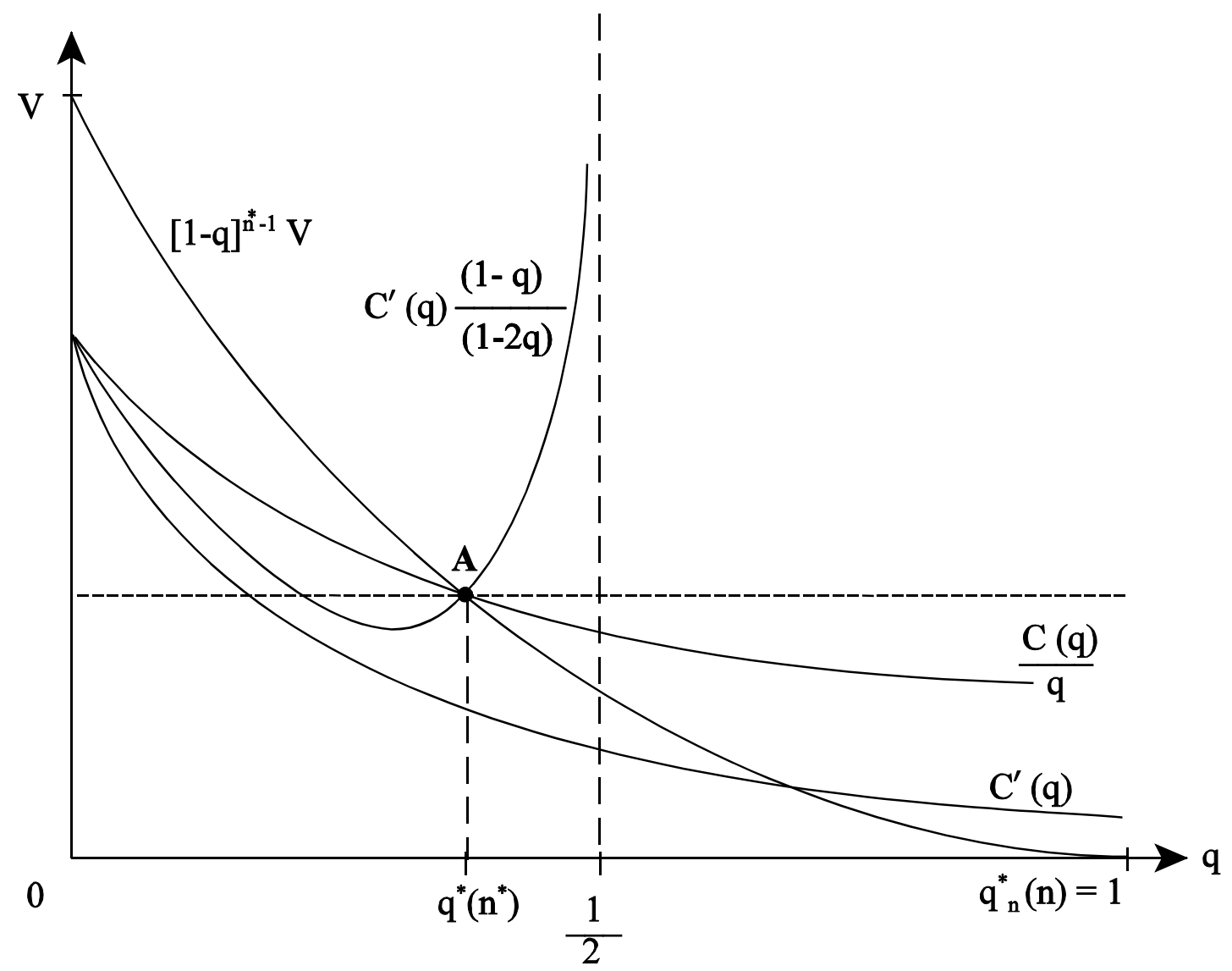

Almost Symmetric Equilibrium with Concave Costs

Figure 10 


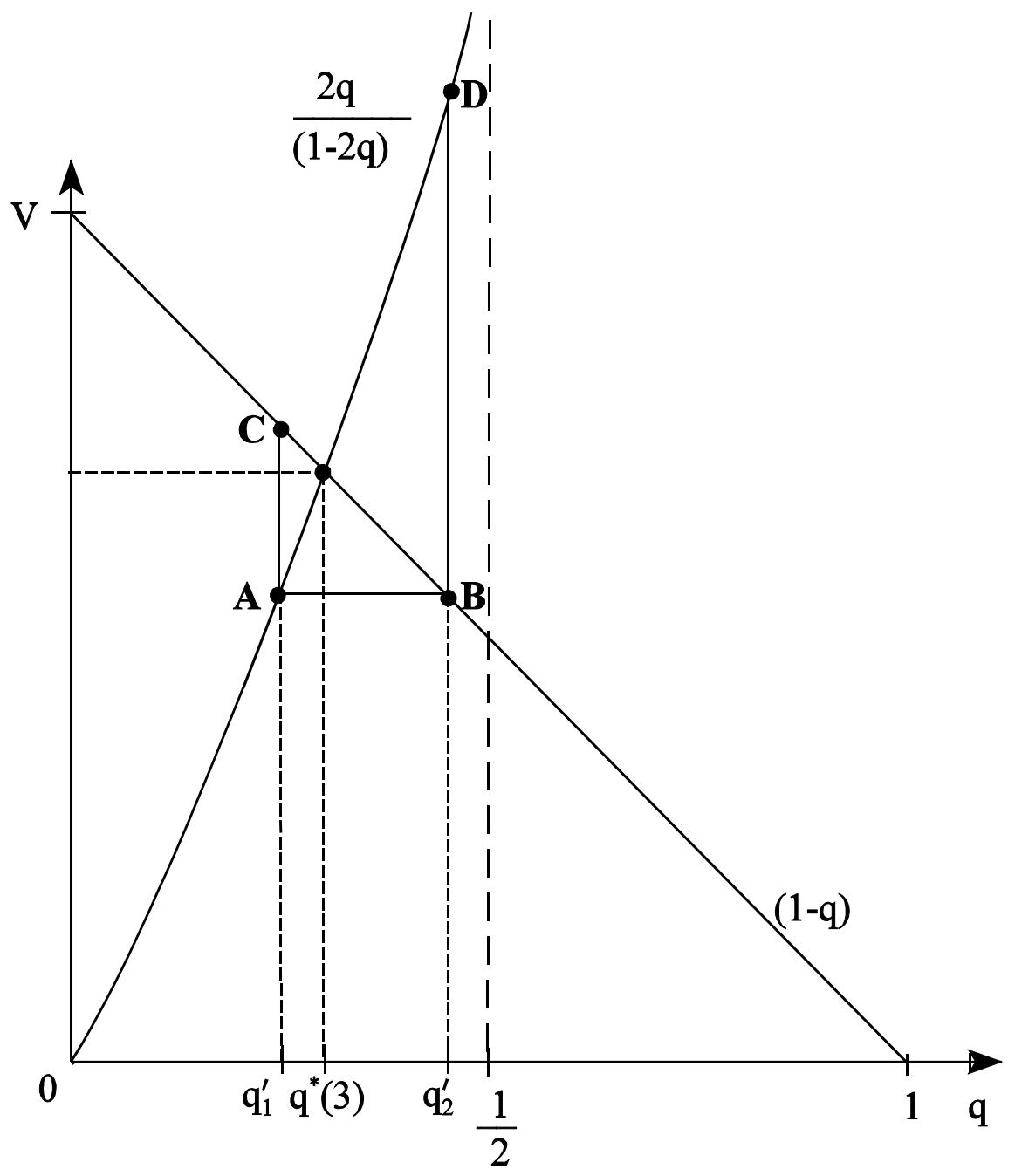

An Example with Convex Costs

Figure 11 